\title{
Miranda
}

Revue pluridisciplinaire du monde anglophone /

Multidisciplinary peer-reviewed journal on the English-

speaking world

19 | 2019

Rethinking Laughter in Contemporary Anglophone Theatre

\section{Breaking Virginia's Waves (1931): from page to stage}

Jean-Rémi Lapaire

\section{OpenEdition}

\section{Journals}

Electronic version

URL: http://journals.openedition.org/miranda/22797

DOI: 10.4000/miranda.22797

ISSN: 2108-6559

\section{Publisher}

Université Toulouse - Jean Jaurès

Printed version

Date of publication: 7 October 2019

\section{Electronic reference}

Jean-Rémi Lapaire, "Breaking Virginia's Waves (1931): from page to stage", Miranda [Online], 19|2019,

Online since 15 October 2019, connection on 16 February 2021. URL: http://journals.openedition.org/ miranda/22797 ; DOI: https://doi.org/10.4000/miranda.22797

This text was automatically generated on 16 February 2021.

\section{(ब) $(\Theta \Theta$}

Miranda is licensed under a Creative Commons Attribution-NonCommercial-NoDerivatives 4.0 International License. 


\title{
Breaking Virginia's Waves (1931): from page to stage
}

\author{
Jean-Rémi Lapaire
}

\section{Introduction: a "tough read"?}

$1 \quad$ Literary scholars have long considered Virginia Woolf's experimental novel, The Waves (1931), to be her boldest and most accomplished attempt at narrative innovation - a work of fiction "most radically experimental and difficult" (Richardson 1973: 692). Educated readers already familiar with Woolf's method usually delight in the anonymous, depersonalized prose of the "interludes" celebrating the sea, birds and sunlight; the "dramatic soliloquies" of the 6 protagonists; the "self-presentations and self-justifications" of Bernard, Susan, Rhoda, Neville, Jinny and Louis (Flint, 1992: ixxiii); the integration of thought, perception, and shifting perspectives into a single, continuous flow of subjective experience.

[Second interlude: opening sentences]

The sun rose higher. Blue waves, green waves swept a quick fan over the beach, circling the spike of sea-holly and leaving shallow pools of light here and there on the sand (...) Sharp stripes of shadow lay on the grass (...) The sun laid broader blades upon the house.

(Woolf [1931] 2000: 20).

[Second section: "the last day of the last term" has finally come. All must now part and travel back home]

'It is the first day of the summer holidays,' said Rhoda. 'And now, as the train passes by these red rocks, by this blue sea, the term, done with, forms itself into one shape behind me. I see its colour. June was white. I see the fields white with daisies, and white with dresses; and tennis courts marked with white. Then there was wind and violent thunder. There was a star riding through clouds one night, and I said to the star, "Consume me". That was at midsummer, after the garden party and my humiliation at the garden party (...) Identity failed me. We are nothing, I said, and fell. I was blown like a feather. I was wafted down tunnels (...)

'Now we are off,' said Louis. 'Now I hang suspended without attachments. We are 
nowhere. We are passing through England in a train. England slips by the window, always changing from hill to wood, from rivers and willows to towns again. And I have no firm ground to which I go (...) I go vaguely, to make money vaguely. Therefore a poignant shadow, a keen accent, falls on these golden bristles, on these poppy-red fields, this flowing corn that never overflows its boundaries; but runs rippling to the edge. This is the first day of a new life, another spoke of the rising wheel.

(Woolf [1931] 2000: 47-48).

But the common reader - including the average English literature student - may not be so ecstatic when confronted with Woolf's 230-page volume. The process of interpretation turns out to be quite challenging, for The Waves is novelistic, yet does not read like a novel. It is equally poetic, yet does not read at all like a poem. The Waves is a unique, unclassifiable piece of fiction that defies all attempts at categorization - a protracted narrative, intensely lyrical and deeply metaphysical, which does not belong anywhere.

[Seventh section: midlife. The internal perspective has just shifted from the earthly and motherly Susan, reflecting on her rural surroundings and family life, to the promiscuous, London-loving Jinny, who "still excites eagerness" (in males) but is "no longer young" and knows that men already "seek some other face"]

'Here I stand,' said Jinny, 'in the Tube station where everything that is desirable meets - Piccadilly South Side, Piccadilly North Side, Regent Street and the Haymarket. I stand for a moment under the pavement in the heart of London. Innumerable wheels rush and feet press just over my head. The great avenues of civilisation meet here and strike this way and that. But look - there is my body in the looking glass. How solitary, how shrunk, how aged! I am no longer young. I am no longer part of the procession (...) Lifts rise and fall; trains stop, trains start as regularly as the waves of the sea. This is what has my adhesion. I am a native of this world, I follow its banners (...) Therefore I will powder my face and redden my lips. I will rise to the surface, standing erect with the others in Piccadilly Circus. (Woolf [1931] 2000: 148-49)

3 Although The Waves baffles ordinary readers and often puts their patience and resilience to the test, it is a tightly structured narrative, which is neatly divided into nine autonomous sections. Each opens with an italicized poetic prelude - or "interlude" -, which evokes a particular time of day, from dawn to dusk. The "interludes" are arranged in a strict chronological sequence. All contain a sensory evocation of "the progress of the sun through a single day" that has both a symbolic and prefatory function: the positions of the sun and the changing quality of light connect with "phases in the characters' lives" and "intertwined subjectivities" (Clements 2005: 163-66): playing, squabbling, attending lessons together at the nursery; going to boarding school; exploring the adult world; torturing themselves and eventually finding themselves; meeting up in London then parting again; coping with the accidental death of Percival (their common friend - sensuous, fascinating but thoroughly hollow); grieving; struggling with desire or disillusionment; reaching middle age; experiencing a final sense of separation, incompletion and loss. As the day unfolds, life unfolds; as the sun travels across the sky, Bernard, Susan, Rhoda, Neville, Jinny and Louis metaphorically travel along the path of destiny, from childhood (the rising sun, the early morning light) to maturity and death (the sinking sun, darkness flooding in):

[Ninth interlude: nightfall]

Now the sun has sunk. Sky and sea were indistinguishable (...) The tree shook its branches and a scattering of leaves fell to the ground (awaiting) dissolution (...) 
Dark shadows blackened the tunnels between the stalks. The thrush was silent and the worm sucked itself back into its narrow hole (...) As if there were waves of darkness in the air, darkness moved on, covering houses, hills, trees, as waves of water wash round the sides of some sunken ship.

(Woolf [1931] 2000: 181)

[Ninth section: Bernard's closing monologue - a lyrical summing up]

'I said life had been imperfect, an unfinished phrase (...) And now I ask, "Who am I?" I have been talking of Bernard, Neville, Jinny, Susan, Rhoda and Louis. Am I all of them? Am I one and distinct? I do not know. We sat here together. But now Percival is dead, and Rhoda is dead; we are divided; we are not here (...) Death is the enemy. It is death against whom I ride with my spear couched and my hair flying back like a young man's, like Percival's, when he galloped in India. I strike spurs into my horse. Against you I will fling myself, unvanquished and unyielding, o Death!

The waves broke on the shore. ${ }^{1}$

(Woolf [1931] 2000: 218-28)

4 The Waves has a simple linear structure, which readers may safely rely upon as they work their way through the characters' multifocal and loosely connected monologues. Remarkably, a cyclical pattern is superimposed upon the time line: just as the waves "arch their backs" and tirelessly "break on the shore," only to "rise", "swell" and form again (Woolf [1931] 2000: 228), the first-person soliloquies "mass themselves" and "spread" (Woolf [1931] 2000: 112), one after the other, over and again. Ultimately, the myriad events reported by characters - material, mental, perceptual, or emotional are blended into a single "substance" that is "made (up) of (all the) repeated moments run together" (Woolf [1931] 2000: 171). This shared experiential "substance" is not so easy to grasp in the first place, but readers eventually come to an understanding that this very "substance" is the true fabric of the novel, the very stuff that life is made up of, as Bernard himself explains in his final soliloquy:

'The illusion is upon me that something adheres for a moment, has roundness, weight, depth, is completed. This for the moment seems to be my life. It it were possible, I would hand it you entire. (...) Let us pretend that life is a solid substance, shaped like a globe, which we turn about in our fingers (...) The globe of life, far from being hard and cold to the touch, has walls of thinnest air. If I press them all will burst (...) What I call "my life", is not one life that I look back upon; I am not one person; I am many people; I do not know altogether who I am - Jinny, Susan, Neville, Rhoda, or Louis: or how to distinguish my life from theirs.

(Woolf [1931] 2000: 183-212)

The question nonetheless remains as to what makes reading The Waves so daunting, despite the regularity and strict patterning displayed. A likely reason is that language use, not formal structure, is responsible for the difficulty. For the simplest, most elementary rules of ordinary verbal interaction are intentionally flouted by the narrator(s), and this is not without serious consequences for the reader. Although Woolf establishes her protagonists as credible social actors from the outset, she hardly ever shows them talking and responding to each other, face-to-face, even when direct speech is used, and despite the omnipresent single quotation marks. There are few (if any) instances of "conversation or dialogue": only "reports" and "evidence of something like overhearing" (Miko 1988: 66). It is a striking feature of the novel that some kind of inner/private language - or "language of thought" (Fodor 1975: 56) generally substitutes for actual speech (or "public language"); that whenever characters are shown talking, they do not really address anyone in particular and mostly seem to be talking to themselves, in a vacuum, or to some generic person - 
abstract, unspecified, and utterly disembodied - or else to the group as an implied "community of consciousness" thinking in unison (Hild 1994: 69):

[Fourth section: the six friends are sitting inside a London restaurant, celebrating Percival's imminent departure to India. They are "about to part"]

'Do not move, do not go. Hold if for ever' (said Louis)

'Let us hold it for one moment,' said Jinny; 'love, hatred, by whatever name we call it, this globe whose walls are made of Percival, of youth and beauty, and something so deep sunk within us that we shall perhaps never make this moment out of one man again.'

'Forests and far countries on the other side of the world,' said Rhoda, 'are in it; seas and jungles; the howlings of jackals and moonlight falling upon some high peal where the eagle soars.'

'Happiness is in it,' said Neville, 'and the quiet of ordinary things.'

(Woolf [1931] 2000: 109)

6 Direct communicative interaction, regular forms of dialogue and interpersonal manipulation are virtually non-existent, as opposed to what normally happens in ordinary, situated uses of speech. To complicate matters further, variation in delivery style and speaker idiosyncrasy are unmarked: vocabulary and syntax strike the reader not only as stylized but strangely uniform across age, class and gender, even if subtle "distinctions between characters" exist that the perceptive reader "begins to distinguish" after some time (Hild, 1994: 70).

Equally disturbing is the "monotony," unnaturalness and general indeterminacy of utterance acts throughout the novel (Richardson 1973: 693). As ordinary users of the language, readers may legitimately wonder who is actually being spoken to when anyone says anything; why the speech of young children and adolescents is so inauthentic and unidiomatic ${ }^{2}$; why there is such a profusion of disconnected statements and reflections; how relevant are the random thoughts and sensations to the situation.

8 Freeing oneself from ordinary socio-pragmatic constraints, disregarding conventional expectations is double-edged: powerful stylistic effects are created, narrative technique and literary aesthetics enhanced, yet, at the same time, special demands are made on the reader that may be stressful. For language is a semiotic system that both reflects and enforces social "convention" (Langacker 2008). The willing suspension of conventionality - the adoption of unconventional semiotic rules - is necessarily disturbing and requires extra processing time and effort, even for the most flexible, and open-minded reader.

\section{From page to screen or stage}

\subsection{A lesson from the arts}

The critical interpretation of a literary work of such complexity as The Waves (1931) is usually left to scholars and literature teachers, using well established forms of analytic or argumentative discourse - typically the formal talk or lesson, the classroom or seminar discussion, the essay or article, and the (close-) reading exercises. All are patterned and ritualized: participants are assigned strict socio-interactional roles - "speaker" vs. "listener"; "teacher" vs. "student"; "literature specialist" vs. "non-expert reader" - and expected to follow the associated behavioural codes, which include spatial, kinetic and vocal requirements. Speakers may stand or sit, while controlling their use of voice and 
gesture. Listeners and readers are expected to restrain their movements and express themselves only when asked to do so. This is the default teaching-and-learning scenario, which is meant to create favorable conditions for studying literature in Higher Education.

There are many ways in which this traditional conception may be challenged. As will be shown later, other strategies and configurations exist that make a fuller use of our shared embodied cognitive and semiotic abilities. The "learning body" of literature students may be encouraged to engage in dynamic acts of understanding (Lapaire 2019): this is the "literature in the flesh" scenario that I have been implementing for some time at my home university and at various workshops or Summer schools. I have been rethinking educational space and activities in literature classes so that the sensing, moving and cognizing bodies of teachers and students may produce physical displays of meanings and a coordinated understanding of literary works. When this happens, the process of interpretation ("explaining", "understanding") is stretched beyond intellection. Some kind of physical performance is involved, and some kind of translation/adaptation takes place that draws teachers and students beyond the confines of the sacrosanct printed page. Participants are encouraged to enrich and diversify their spoken or written "discussion" of a given piece: essays and term papers are maintained, but script-writing, reflective journaling, recitation, stage direction, etc., are added to the list of activities used for teaching, learning and evaluation.

11 Although this approach to teaching literature may sound unusual (and possibly unsettling) to most college and university educators, the thematic and semiotic appropriation strategy that has just been described is standard practice in the arts. No playwright or scriptwriter, no video or film director, no choreographer or music composer, and of course no student willing to embrace these professions would survive for long without the ability to transform and perform existing material, to change or adapt the original medium used by some author. Transformation is a professional skill that all artists and art teachers share. It allows them to revisit, reprocess, reframe "things" of any kind, and this of course includes cultural objects, concrete and abstract, literary and non-literary.

In her 2:13 minute "book trailer" advertising The Waves, the young Russian film director Daria Darinskaya (2015) uses a clever combination of "interlingual" (English-toRussian) and "intersemiotic" translation (textual-to-pictorial, written-to-spoken, static-to-dynamic). ${ }^{3}$ Her aim is to introduce Virginia Woolf's 228-page novel to Russianspeaking readers in little more than 120 seconds, with the highest level of concision and efficiency. She achieves an extraordinary degree of poetic compression and succeeds in choreographing physical displays of meanings - powerful and haunting. Darinskaya's "trailer" is intense, synthetic and visually explicit, yet remains enigmatic enough to arouse curiosity and avoid distortion or oversimplification. The hypnotic black and white video captures the essence of The Waves - a seemingly impossible task - in just a few shots and a short succession of voice-over comments. The pictures are mainly close-ups of the 6 protagonists and their common friend Percival; dinner scenes; an evocation of Woolf writing at her desk; smart phones lighting up faces in the dark; waves swelling and breaking. Personal identity, strong emotions (loving then mourning Percival), and a fleeting sense of togetherness (when they are reunited in London) are the most salient themes. 
Figure 1

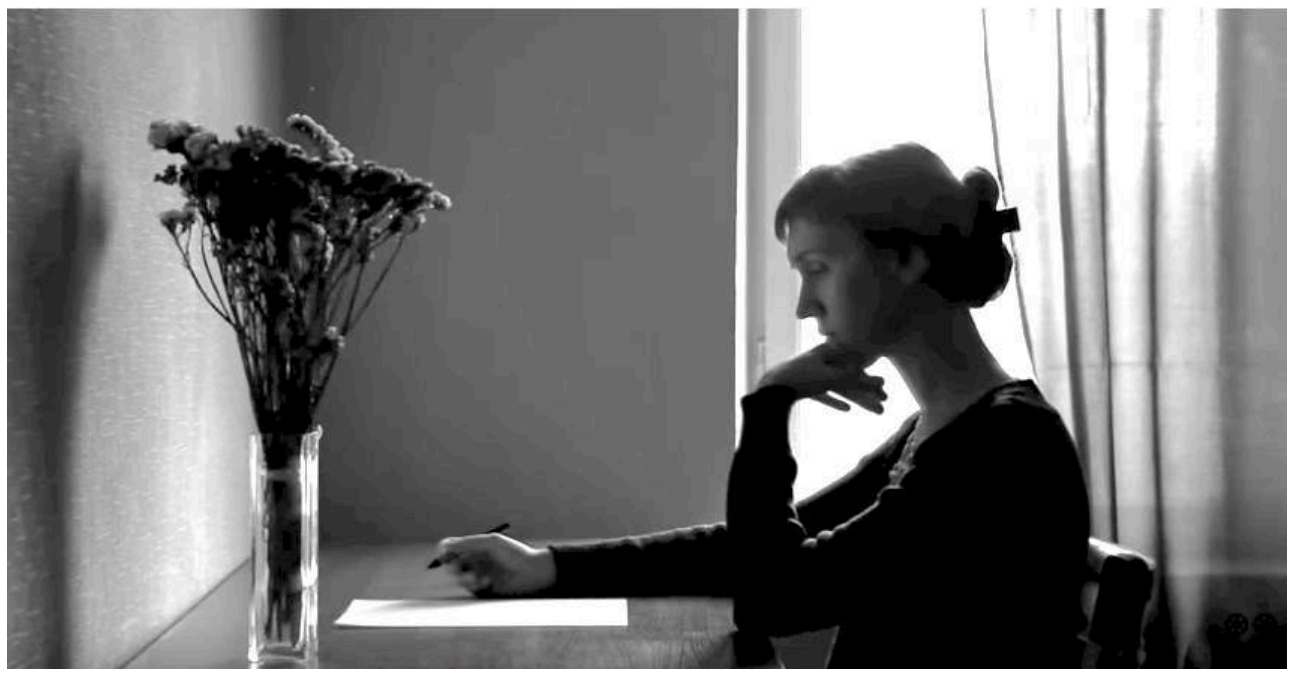

The Waves: a book trailer (Darinskaya 2015)

The narrative process ("The idea of some continuous stream") (voice-over)

Figure 2

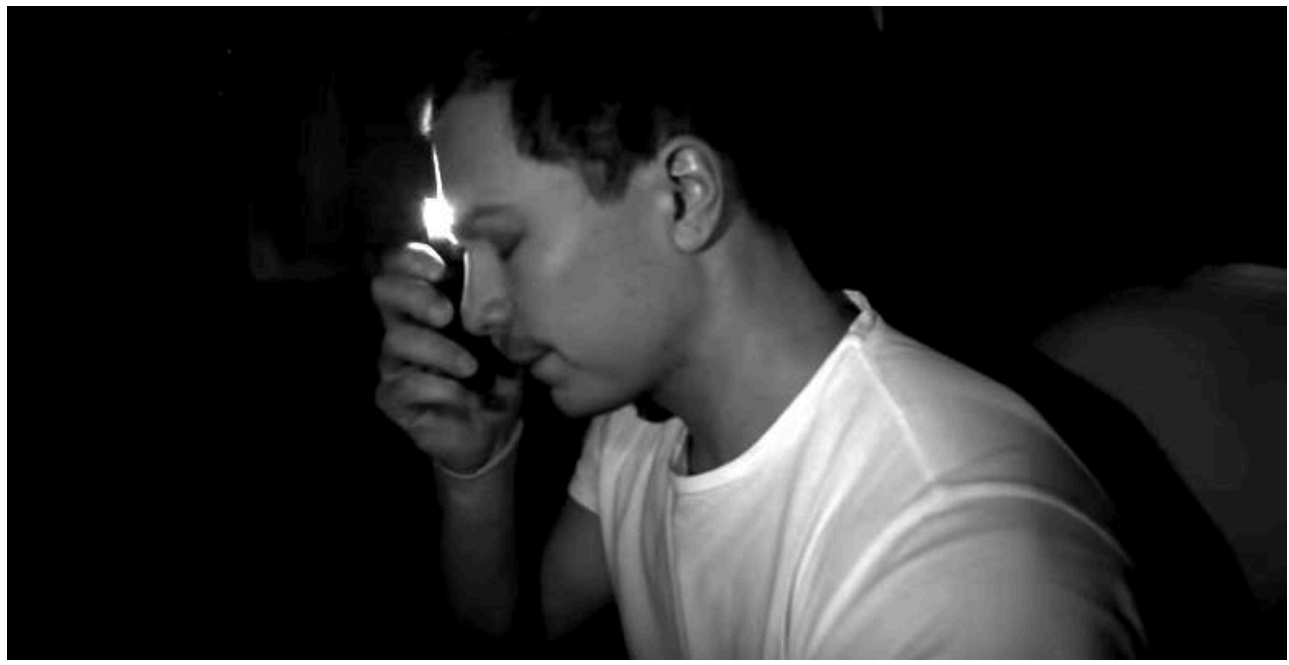

The Waves: a book trailer (Darinskaya 2015) - Neville

"Percival will forget me" (voice-over commentary in Russian) 
Figure 3

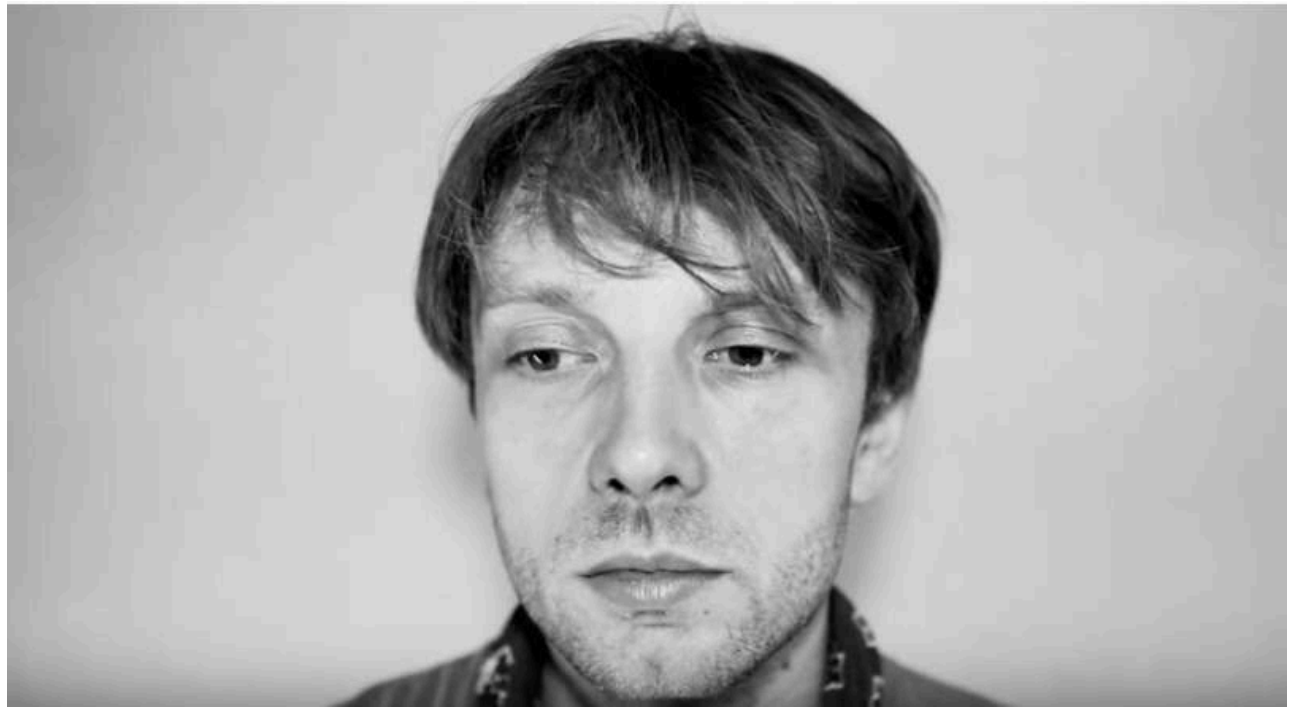

The Waves: a book trailer (Darinskaya 2015) - Bernard

"What has happened to my world?" (after Percival's death) (voice-over)

Figure 4

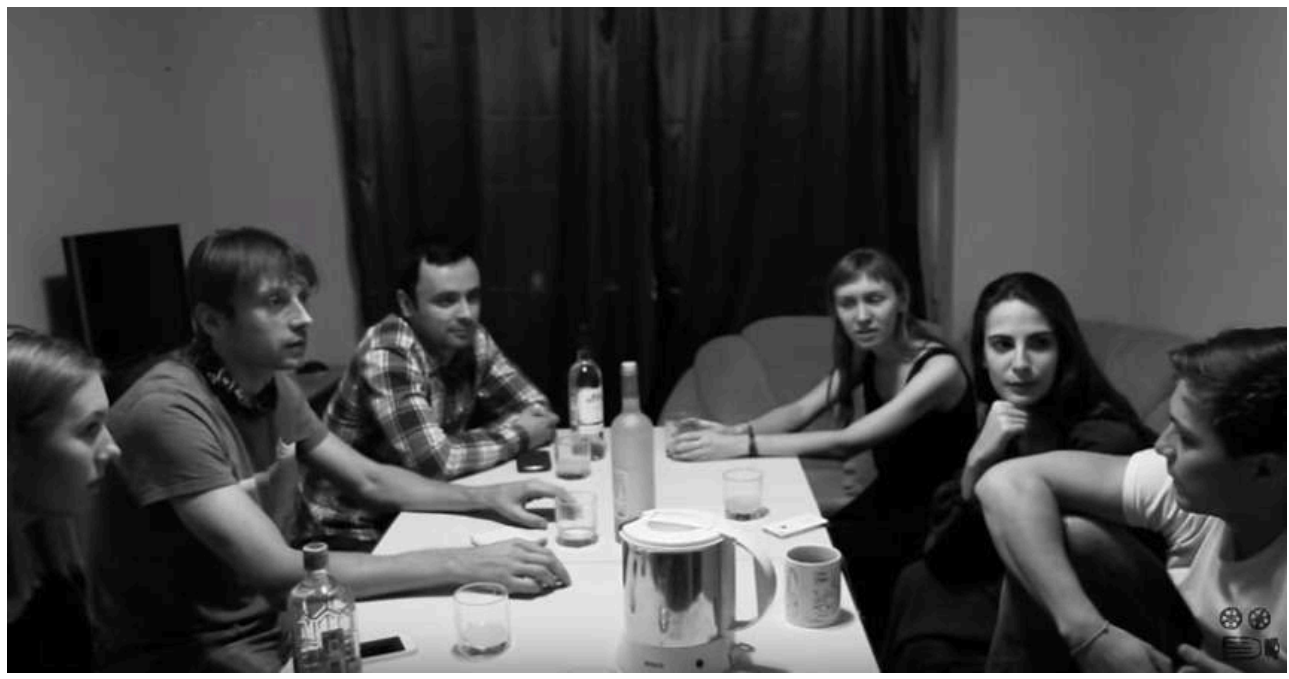

The Waves: a book trailer (Darinskaya 2015)

Dinner scene (muted, stroboscopic) 
Figure 5

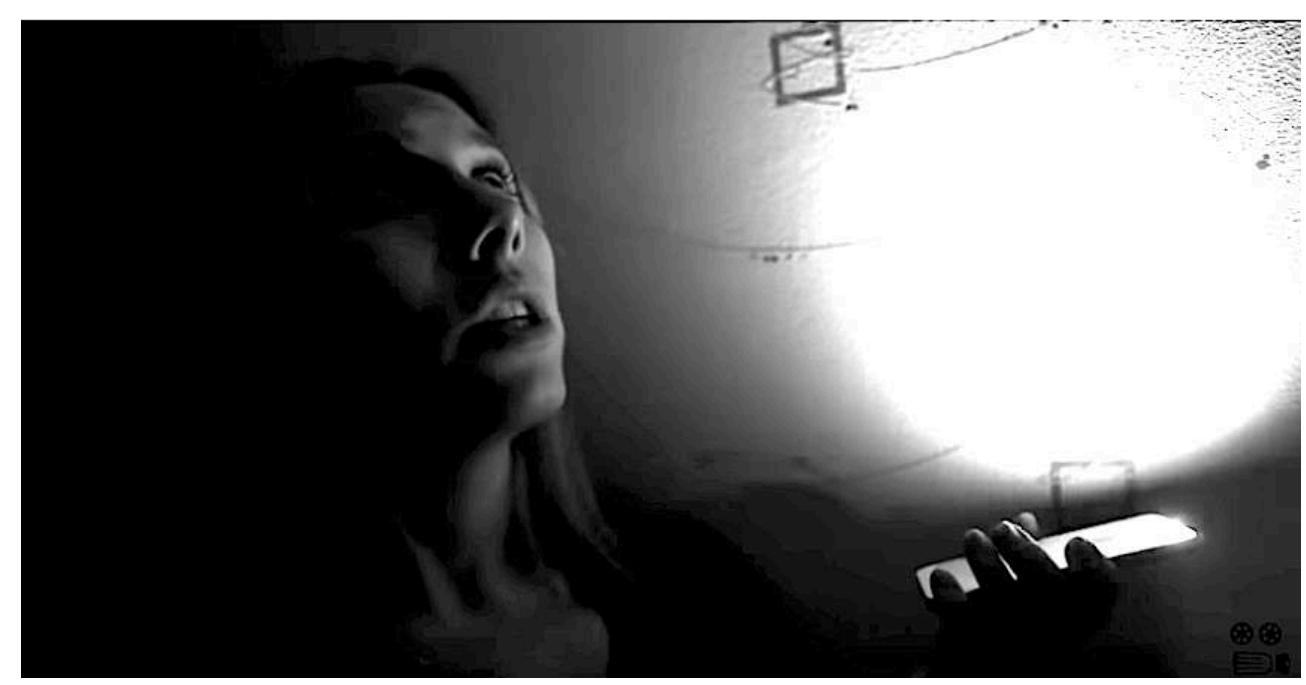

The Waves: a book trailer (Darinskaya 2015) - Susan

"I have been knotted. I have been torn apart" (Neville's words) (voice-over)

13 Another instance of resemiotisation that is most relevant to literary studies is Wayne McGregor's "ballet triptych" - Woolf Works (2015), which was commissioned by the Royal Ballet, and set to music by Max Richter. As explained in a documentary film produced by the Royal Opera House (Nunnely 2017), both movement and music were used to "translate (Mrs Dalloway, Orlando, The Waves) into something for the stage." The production met with instant public and critical acclaim. McGregor's inspired choreographic pieces used kinetic action to capture the "essence" of his literary sources, building on the rich imagery and abundant sensory cues that were present in Woolf's three narratives. Patterned dance movements were successfully used to resemiotise the characters' interactions, inner monologues and relationships, like "solitude," "mental confusion", "restlessness" and "psychological entwinement," which lend themselves well to choreographic expression. 
Figure 6

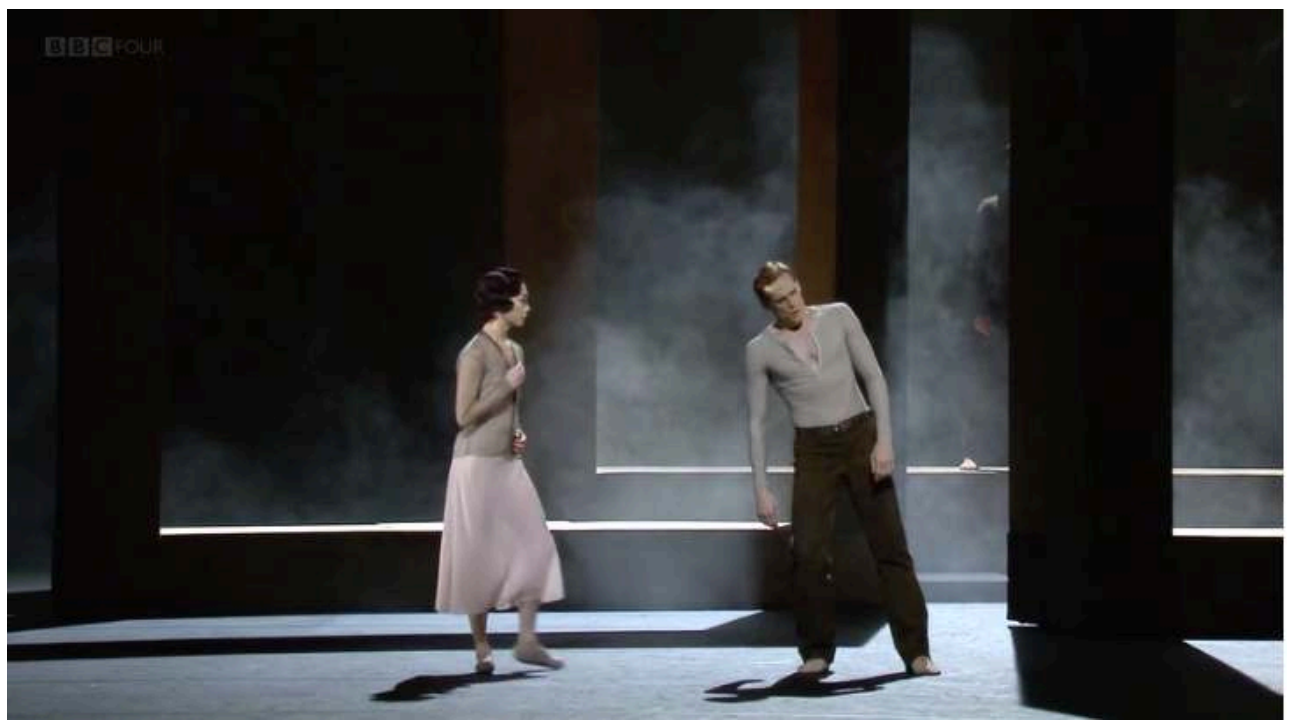

Woolf Works (McGregor 2015 - The Royal Ballet): Mrs Dalloway Lucrezia's attempt to break into Septimus's tortured world

Figure 7

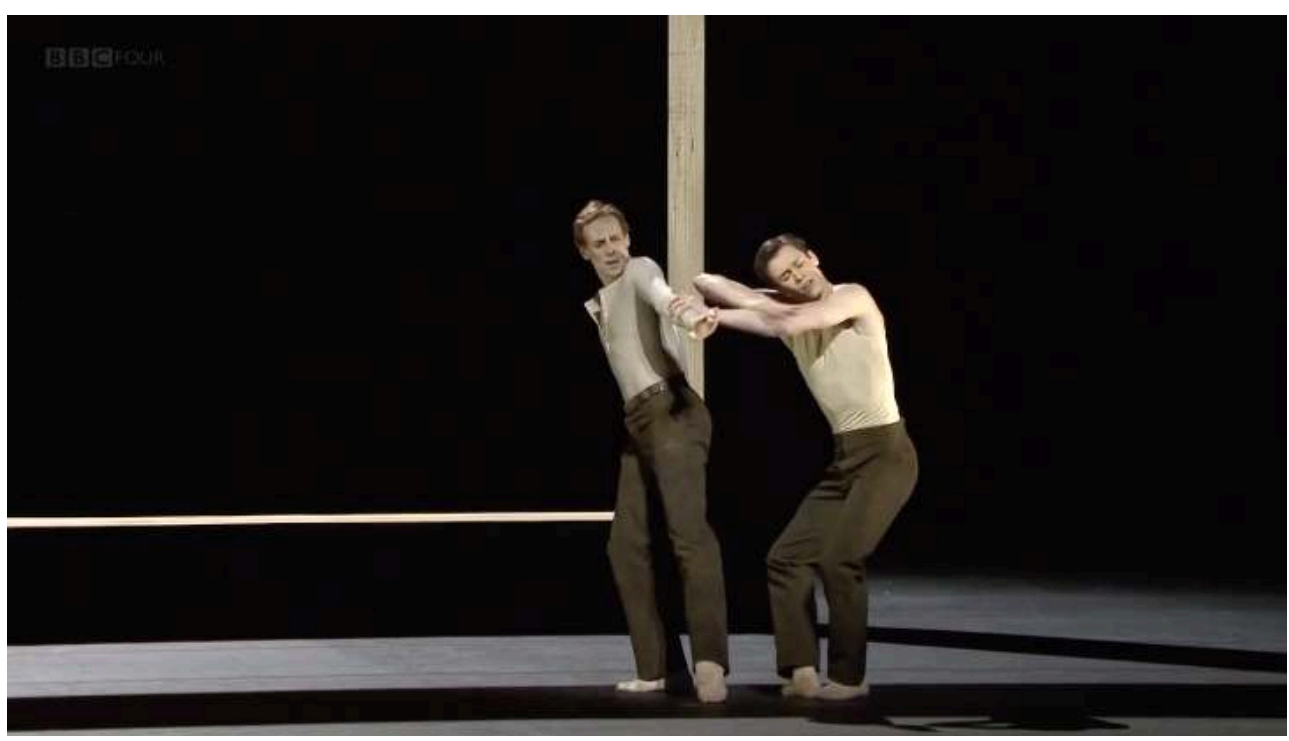

Woolf Works (McGregor 2015 - (c) BBC): Mrs Dalloway

Septimus and Evans ("that man (...) his officer (...) who was killed")

Psychological entwinement between the living and the dead

14 McGregor's visual-kinetic "translation" is consistent with the characters" "energy" and "dynamic" as they explore time and space in the stories. It is powerful enough to "get to the core of what these novels were about." As one watches the documentary film or listens to the interviews given by McGregor when the production was revived, one acquires the conviction that a choreographic transposition of this kind operates a performative reassignment of meaning which is conducive to a more holistic kind of understanding, integrating thought, action (movement), and perception (sensation).

The transposition process forces the directors, editors, dance notators, script-writers, music composers, dancers and actors involved to reflect upon the intentions and 
meanings conveyed by the source text, to make motivated decisions as to what needs to be preserved, altered, deleted or highlighted in the final performance. Most importantly, the "re-creators" have to agree on the new semiotic means that will express content (e.g. a combination of recitation, movement, music, still images and filmed scenes, as in Darinskaya's 2015 booktrailer; a mix of music and highly patterned moves in McGregor's 2015 ballet production). The claim made here is that what artists can do - transform and perform, and in the process acquire a more intimate understanding of the source text - students can do as well: they can recreate, explore and experience meanings differently; they can grasp and internalize what might have remained otherwise "distant" or "alien"; they can learn to interpret literary pieces in a joint cognitive, performative and translational sense.

\subsection{Trans-semiotic adaptation}

16 Instruction and learning both require interpretive skills: texts need to be understood, problems and equations solved, meanings construed, phenomena explained (Lapaire 2019). But in mainstream educational practice, the process of interpretation tends to be narrowed to its cognitive dimension alone ("understanding," "construing," "making sense of something"), when other dimensions exist that tend to be marginalized (outside the arts and translation studies):

17 1. engaging in the artistic performance of a piece while displaying one's own sensitivity (as in "interpreting a role" or "a piano sonata");

18 2. translating someone's words into another language (as in "she interpreted for us").

19 All three dimensions of "interpretation", retrievable from the standard definition of the term ${ }^{4}$, may be integrated into a single model for the formation and transmission of knowledge, in whatever social form - ordinary, scholarly, legal, artistic, or other. The union of understanding, performance and translation constitutes the interpretive potential of humans, irrespective of place, time or culture (Lapaire 2019):

Figure 8

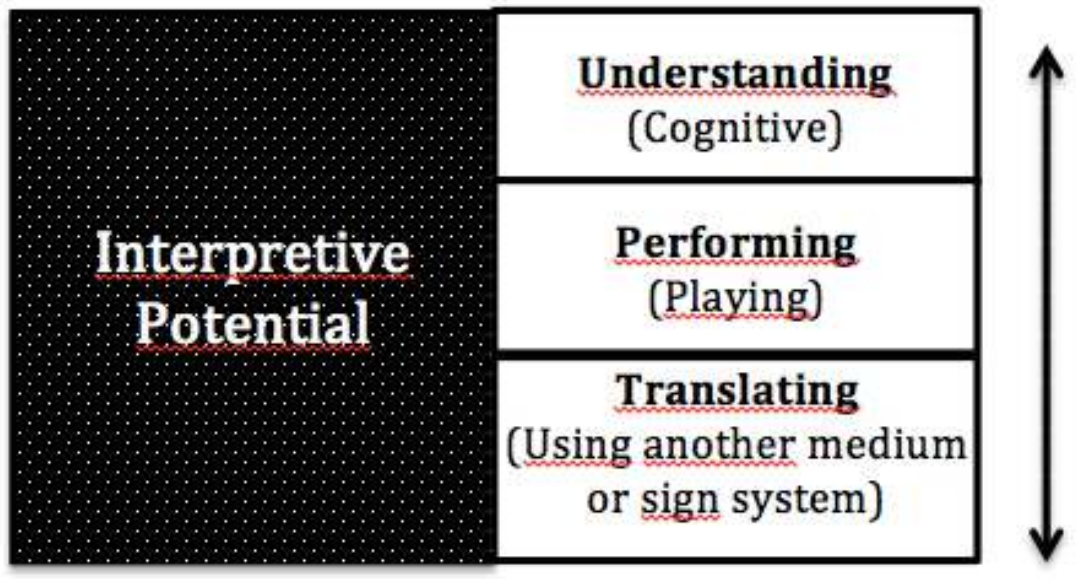

The common interpretive potential: an integrated conception 
20

There are 3 potential roles that a student or teacher might choose to play as they decide to "interpret" something: (1) the expert or scholar who works out the meaning or significance of something, (2) the artist performing a piece with his or her own sensitivity, (3) the language specialist who acts as an intermediary between two idioms (or forms of expression). My current working hypothesis is that playing these three roles jointly rather than separately can be empowering in educational settings.

21 An important point needs to be made regarding the translational dimension. In a landmark paper on translation, Jakobson (1959: 233) defines "three ways of interpreting (translating) a verbal sign":

1) Intralingual translation or rewording - an interpretation of verbal signs by means of other signs of the same language.

2) Interlingual translation or translation proper - an interpretation of verbal signs by some other language.

3) Intersemiotic translation or transmutation - an interpretation of verbal signs by means of signs of non verbal sign systems. translation" - or "resemiotisation" (Eco 1979, O'Halloran et al. 2016). This consists in using a different medium to make the source text or message accessible. Semiotic form is more than just "language material" that speakers use to "package information." It always matters as form and has a definite impact on what cognitive linguists call "construal" (Langacker 2008) - the way the "thing" or "scene" referred to is conceived and presented to others. This means that any change affecting the expressive medium used will have an impact -subtle or manifest- on the reception of meaning. It follows that the process of resemiotisation goes beyond "repackaging" and will inevitably result in the "reframing" of the original input. The focus might shift, effects might gain or lose in intensity. ${ }^{5}$ For example, McGregor's resemiotisation of the Septimus-Evans friendship as a pas de deux in Woolf Works brings out the homoerotic element more explicitly than the original narrative. It performs the kinetic highlighting of verbal utterances like "I must tell the whole world", "No crime, love", "He drew the attention, indeed the affection of his officer (...) They had to be together, share with each other, fight with each other, quarrel with each other." 
Figure 9

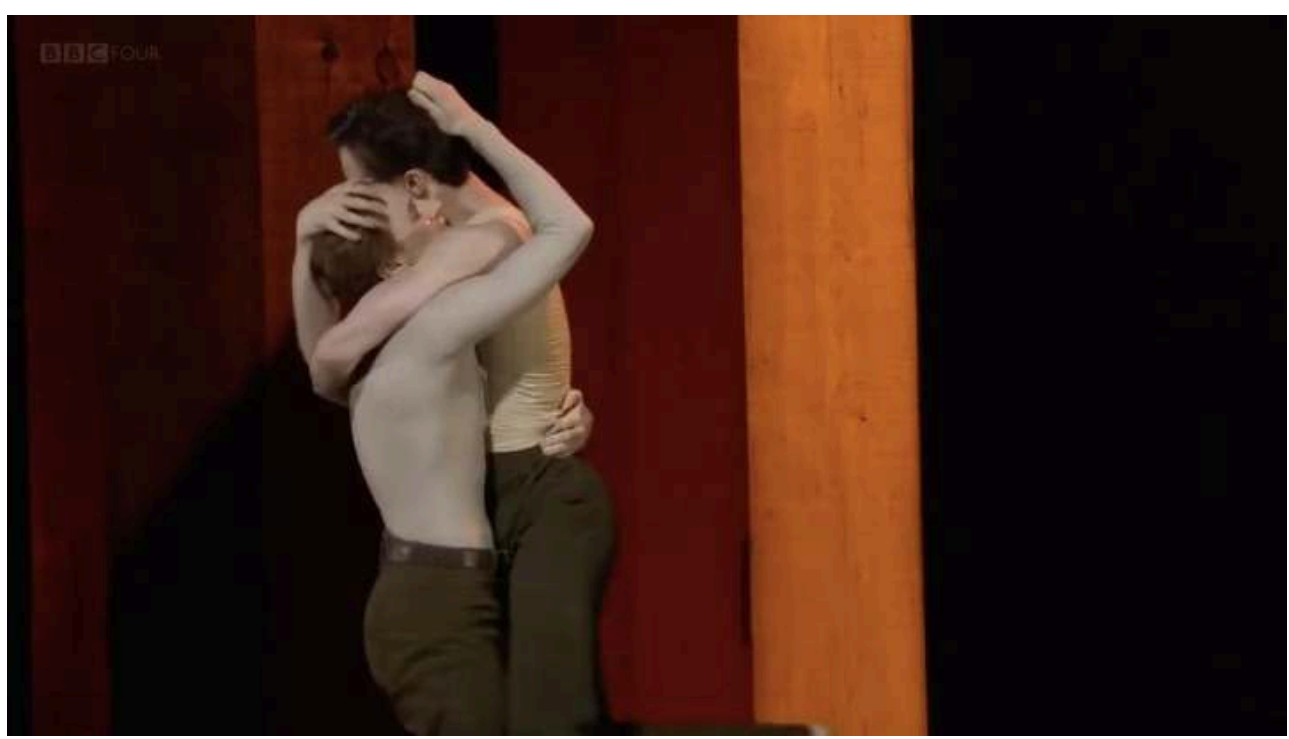

Woolf Works (McGregor 2015 - (c) BBC): Mrs Dalloway

Septimus and Evans: solider and officer inseparable

Writers and artists are experts at "intersemiotic translation," which they use to reshape and recycle existing cultural material. The novelty and artistry of their "creations" should not conceal the fact that transposition and transformation are far more common than pure invention. Many of the most valued and cherished works of art in our culture are trans-semiotic recreations or adaptations, rather than creations in a strict sense. Illustrations of this process, past and present, are plentiful. For example, in European and Asian cultures, oral myths, legends, and folk tales have traditionally been resemiotised as written poems or narratives (sometimes illustrated), drawings, paintings, tapestries, ceramics, folk dances, (court) ballets, puppet shows, musical pieces or some combination of these (as in an opera production integrating painted sets, a printed score and libretto, staged vocal-kinetic expression, choreographic pieces, live orchestral music, etc.).

What might be called intersemiotic circulation across genres and sign systems in the arts is made possible by the innate human ability to absorb, process and express holistically any experiential input, as the French anthropologist Marcel Jousse (1886-1961) remarkably established in his research and teaching. The reason why switching from one semiotic system to another feels so easy and natural, is that human expression is "global" (multimodal). It is based on a process of "play" (Fr. jeu) and "replay" (Fr. rejeu): the things that present themselves to us are perceptually absorbed and work their way into us, i.e. deep into the body-mind compound. This is the impressive phase. What comes to "play" within us becomes available for external "replay" or "re-enactment," using the vast array of semiotic means available for expression - vocal, gestural, scriptural, or other. Jousse $(2005,2010)$ rightly claims that there are no internal semiotic boundaries in the human body-mind compound: the system is whole and fluid, so mixing or changing expressive modalities is the rule (Sienaert 2011). In short, the artistic freedom to resemiotise simply reflects our innate capacity, as sensing and moving creatures, to navigate the entire system of embodied semiotic expression that we live and interact by. We are greatly helped in this by the symbolic plasticity of space and the human body, which may potentially stand for anything or anyone, since the space around us, our 
body parts, our entire bodily frame, can refer to something else than themselves: ideas, events, past or future situations (removed from the present circumstances), people, etc. (McNeill 1992, Calbris 2011).

If symbolic plasticity and the ability to replay and transpose were not defining characteristics of human cognition, then paintings would not be so easily "dramatized" and turned into "tableaux vivant" (literally "living pictures") - a genre that was immensely popular in the $19^{\text {th }}$ century, and which recently came to be revived by Ludovica Rambelli Teatro (La Grande Pittura Prende Vita. Tableaux Vivant di Caravaggio e Michelangelo, 2018-19). ${ }^{6}$ The performers dress up, move around, position themselves in space, and strike a final pose that is iconic of the original painting by Caravaggio (The Raising of Lazarus, c. 1609, Museo Reggionale Messina). The painting itself is a transsemiotic adaptation of a miraculous scene reported in the Gospel (John 11:1-44). The written account, ${ }^{7}$ which Caravaggio used rather freely in his adaptation, is also a product of resemiotisation: it is based on oral story-telling-community narratives that early Christians shared and spread.

Figure 10

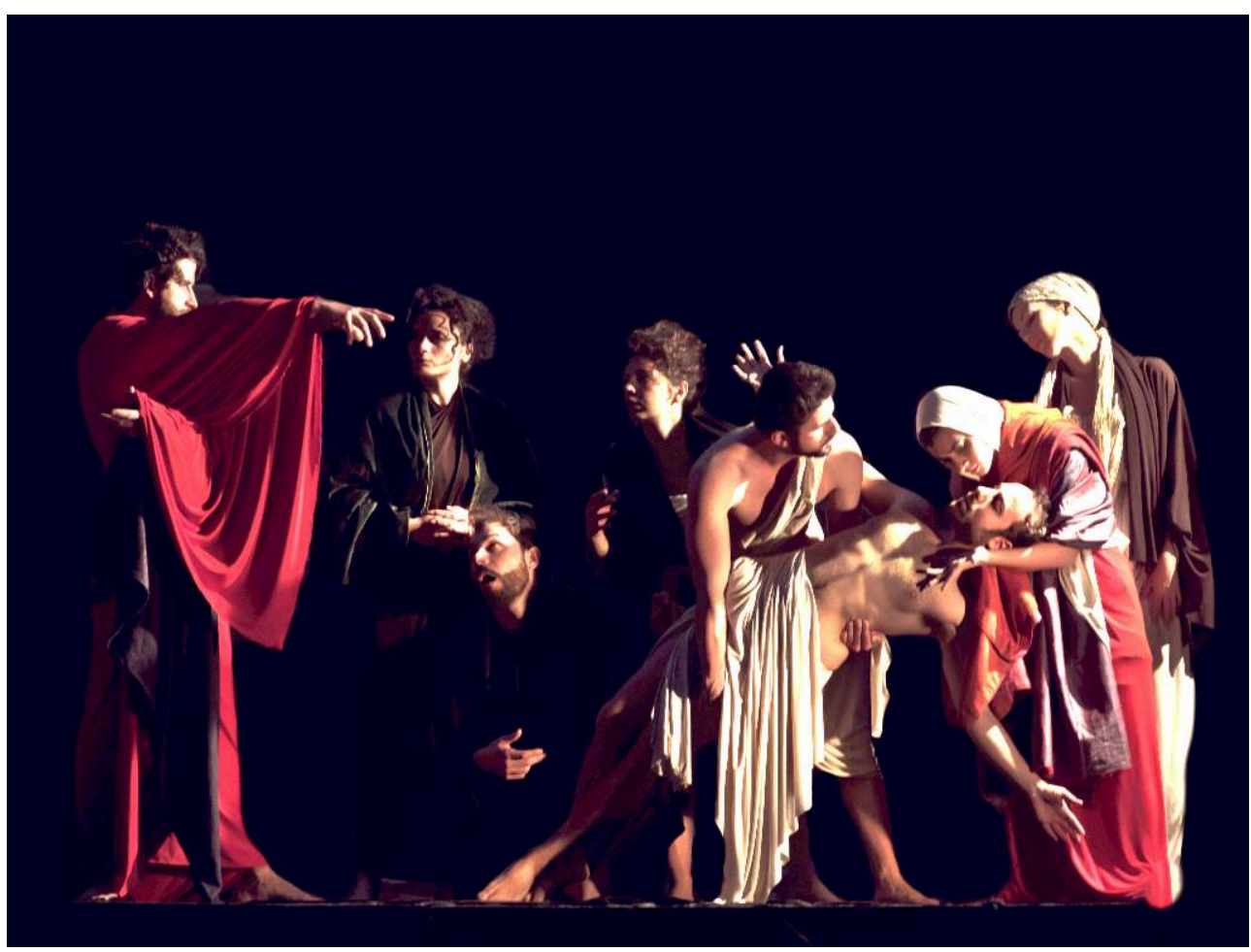

Resurrezione di Lazzaro

(c) Gennaro Paricelli e Compagna Ludovica Rambelli Teatro (2018)

Similarly, if intersemiotic translation was not embedded in our cognitive systems, then the two adaptations of Woolf's works that we discussed earlier (Darinskaya 2015, McGregor 2015) would not "look right" or "feel right." As things stand, Darinskaya's book trailer and McGregor's ballet delight rather than baffle viewers, who are all equipped with the necessary interpretive potential to make sense of the resemiotised pieces. The fact that some aspects of the video or ballet remain inaccessible is not in itself a problem. Humans learn - often at their own expense - that the process of interpretation has its own failures and limitations: some meanings are bound to remain 
obscure, whatever medium is used to express them. Struggling with the incomprehensible, coping with misinterpretation or misrepresentation, are also part of the business of interpretation. Readers of Woolf know this well: there is always much to struggle with in Woolf's experimental fiction, and a large element of mystery left beautiful, unresolved.

\title{
3. Literature in the flesh: embodiment and the performative reassignment of meaning
}

\author{
In reality, humans think with their whole bodies; they think with their hands, with \\ their feet, with their ears, as well as with their brains. It is absolutely ridiculous to \\ claim that their thoughts depend on a part of themselves: it is tantamount to saying \\ that our manual ability depends on our fingernails. " \\ (Jousse 2010 [1974-78]: 73)
}

\subsection{Goals and challenges}

One may safely assume that literature students are no different from ordinary humans: they are interpretive creatures that are mentally and physically equipped to analyze literary works and convey their experience of holistically, in a joint cognitive, performative and translational sense (Figure 8). This is why synergies may be created between reflection, bodily action and trans-semiotic adaptation that empowers subjects and transforms the teaching and learning experience.

29 A striking feature of the "literature in the flesh" workshops is that they are intensely physical: the teaching scenario is built on the idea that "embodiment" is "a powerful force for learning" (Lindgren \& Johnson-Glenberg, 2013: 445), and that "physical effort enhances learning performance" by affecting positively "metacognitive judgements" (Skulmoski \& Rey, 2017: 3). Students go through all the stages leading from the abridgement, re-elaboration and inter-semiotic adaptation of the source text to the final group performance of the new piece - typically a succession of scenes or tableaux vivants, grouped into acts or arranged into "galleries."

It should be clear that performing texts and meanings together in the literature class is intended to supplement - not replace - existing approaches to literature and critical analysis. Students are presented with a variety of literary pieces that are potentially open to compression and resemiotisation. The works may belong to a variety of genres: drama, poetry, fiction, critical or autobiographical essays.

Engaging in interpretive action and orchestrating a performative reassignment of meanings is what the experience is essentially about. As the process unfolds, a shift occurs from "the literary object to the act" (Schewe, 2013:15), from the scriptural to the vocal and gestural. But there are numerous challenges to be met: cognitive (e.g. confusion), kinetic (e.g. stiffness, awkwardness), socio-psychological (e.g. shyness, selfconsciousness, embarrassment), to name but a few. All must be overcome for the experience to be successful. The unusual level of "engagement and artistry" required (Piazzoli, 2018: 317) can only be achieved if the transition between the traditional classroom space (or "standard education zone") and the workshop space (or "temporary kinaesthetic learning zone") is carefully managed (Lapaire 2019). 


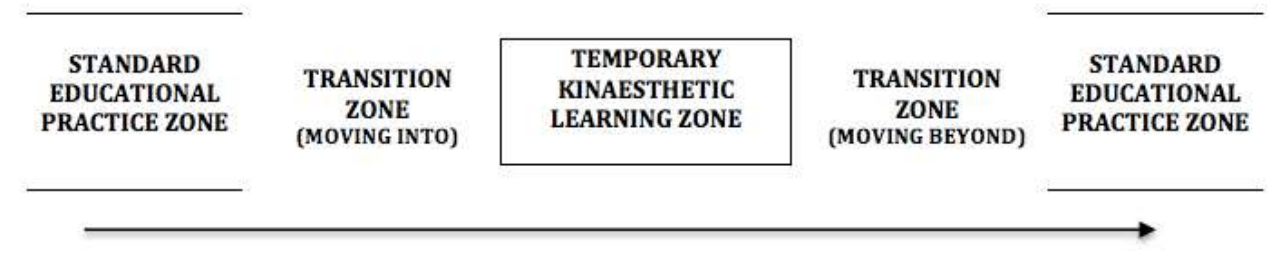

Moving across learning zones (Lapaire 2019)

This is why the presence of guest artists from the dance and theatre worlds is extremely helpful. The guests are expected to act as teachers, directors and transsemiotic mediators between page and stage.

\subsection{Dance and theatre workshops with Melissa Blanc and Oliver Borowski}

Melissa Blanc is a professional French dancer/choreographer who graduated from the Poitiers Conservatory in 2012. She appeared with Compagnie Paul Les Oiseaux in Toutes les filles devraient avoir un poème and Minute Papillon in 2014, and with Compagnie Chatha in Sacré Printemps (2015). Since 2012, she has been a regular guest artist and choreographic advisor at $\mathrm{UBM},{ }^{8}$ co-delivering lecture-performances on language and gesture, ${ }^{9}$ and teaching "literature in the flesh" workshops.

Oliver Borowski is a professional South African actor, director, and drama teacher. After graduating in media, film and journalism (Rhodes University, Eastern Cape, SA) he studied physical theatre in Berlin (2006-08), and eventually moved to Bordeaux where he co-founded Theatre Thump! (2008) with Carole Deborde. Since 2017, he has been teaching "literature in the flesh" and "pragmatics in the flesh" workshops at UBM. He is currently writing a master's dissertation on the physicality of speech and drama-based approaches to language teaching.

Melissa Blanc and Oliver Borowski both contributed to the previous Woolf project Performing Mrs Dalloway (Lapaire 2018) - but worked with separate groups of students, belonging to different schools and age groups. This new project - Breaking Virginia's Waves $^{10}$ brought them together for the first time in the same place. Favourable conditions were created for them to share insights, pool artistic resources, and ultimately co-direct the trans-semiotic adaptation of The Waves at the University Arts Centre ${ }^{11}$ from February to April 2019. Melissa and Oliver were invited to run the extended 3-hour "middle workshop" together. This collaborative "teaching moment" was very special: a single, blended space emerged, integrating the individual strategies for multimodal resemiotisation that they had previously developed with the group, in their own fields of expertise.

During the workshops, ${ }^{12}$ Melissa and Oliver used the warming-up and preliminary exercises to teach students some elementary dance and theatre skills. Melissa Blanc paid special attention to concentration, coordination and group discipline; balance, posture and alignment; gravity and floor-work; walks, runs and falls (forward, backward, to the side), and finally the dialectics of "impression" and "expression." ${ }^{13}$ 
Oliver Borowski insisted on developing the proper attitude in theatre practice "looking, listening, risk-taking" - as well as "taking the space" and "taking one's time." He advised students to strive for "clarity and simplicity" when creating imagery. He reminded participants that they needed to "establish a horizon" and pay special attention to perspective and viewing arrangements in the theatre: whatever one chooses to perform on the stage is always being watched by someone "out there" in the house. The spectator's presence has to be acknowledged at all times. This has a decisive impact on posture and concentration. Oliver had students also working on articulation and voice projection; "action-and-reaction" sequences; "pushing-and-pulling" configurations. Finally, "quality of motion" was explored in depth. Basic movement patterns were subjected to variations in speed, rhythm, emotion, "element" (fire, earth, wind, water), "colour" (black, blue, green, red, yellow, and white), and "time of day" (dawn, morning, noon, afternoon, evening, night). Students were now ready to give physical expression to meanings initially couched in writing.

Table 1

\begin{tabular}{|l|l|}
\hline PROLOGUE & $\begin{array}{c}\text { (“Take it. This is my life." Based on Bernard's } \\
\text { protracted final monologue) }\end{array}$ \\
\hline ACT 1 - Morning & (Childhood - Adolescence - Early Adulthood) \\
\hline Scene 1 & (The Nursery) \\
\hline Scene 2 & (Boarding school) \\
\hline Scene 3 & (College and the real world) \\
\hline ACT 2 - Noon & (Adulthood - Percival's death) \\
\hline Scene 1 & $\begin{array}{c}\text { (Celebrating Percival's departure to India in a } \\
\text { London restaurant) }\end{array}$ \\
\hline Scene 2 & (Percival dies) \\
\hline Scene 3 & (Settling in life - Grief) \\
\hline ACT 3 - Late afternoon - Evening & (Middle age) \\
\hline Scene 1 & (The Years) \\
\hline Scene 2 & $\begin{array}{c}\text { (Last reunion in London - Walking by the } \\
\text { river together) }\end{array}$ \\
\hline EPILOGUE & $\begin{array}{c}\text { (“And in me too the wave rises" - Echoes the } \\
\text { Prologue. Based on Bernard's final monologue) }\end{array}$ \\
\hline
\end{tabular}

Structure of the play

Below is an illustrated summary of the main stage actions that were designed during the workshops, under the artistic supervision of Melissa and Oliver. The piece opens with a physical evocation of the sea. The students first position themselves around the stage, facing the audience. A soundscape is created: the wind, the sea birds, the distant horn blasts, the swell, the ebb and flow of spent waves. Splashing, hissing, cawing, chirping, wailing, drumming, thudding noises are produced. Bodies stand erect, barely moving. 
Figure 12

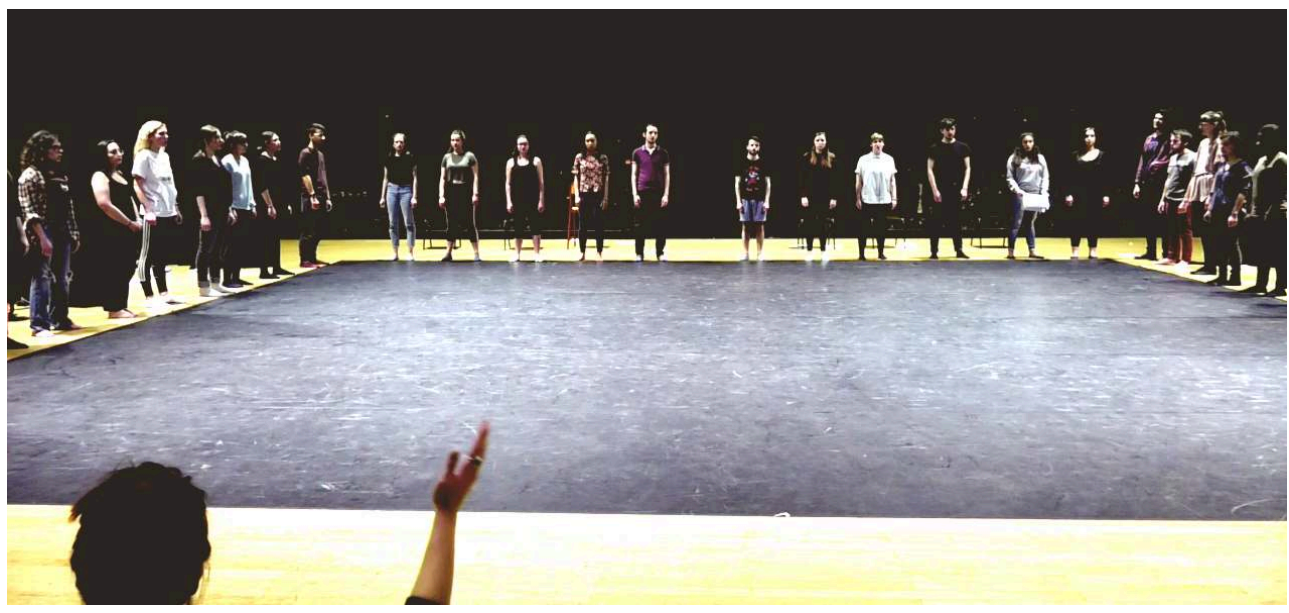

Creating a soundscape

The performers now split into three groups, and travel across the stage in short successive runs, stopping midway, tipping over, falling to the ground, lying across the floor, picking themselves up, and finally retreating, as the next (human) wave swells, propels itself forward, and eventually rolls onto the beach, only to be sucked back again. This is the main kinetic leitmotiv of the performance that runs through the entire piece. What the actors are now performing with their bodies, Bernard will express verbally later, in the closing lines of the Epilogue: "This is the eternal renewal, the incessant rise and fall and rise again! The waves forever breaking on the shore."

Figure 13

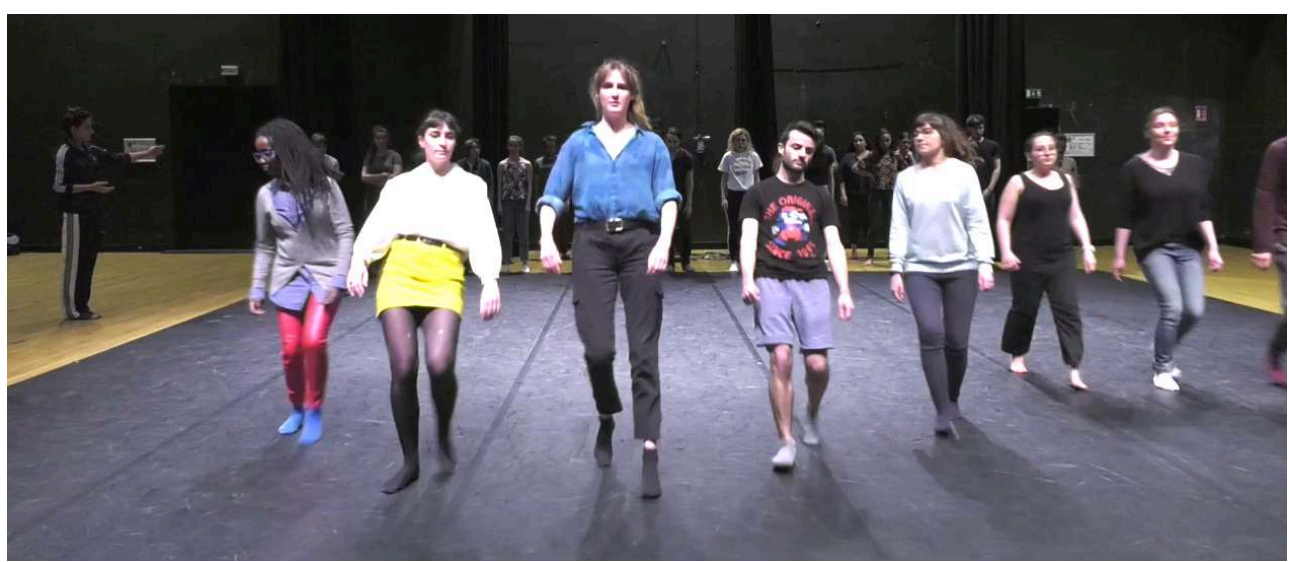

Waves breaking and receding

The actors regroup, bunch up together and perform a series of coordinated arm movements - a metaphor for the early bonding of the 6 friends at nursery school. Bernard suddenly freezes, then steps aside and says - "I am not one person, I am many people - Bernard, Neville, or Louis; Susan, Jinny or Rhoda. I am all of them." It is now Rhoda's turn to break away from the group. She looks lost and wild. She erupts: "Who and what are these unknown people? What are stories?" The others grip her and try to hold her back, but she wrenches herself free and struggles to get away, screaming madly, until Jinny steps in and proclaims: "There is always a story. I am a story!" 
41 The students now perform the scenes or tableaux that they have designed and rehearsed at home in small groups of 4 to 6 . They are free to choose which moment inspires them most, and make whatever cuts they deem appropriate.

Figure 14

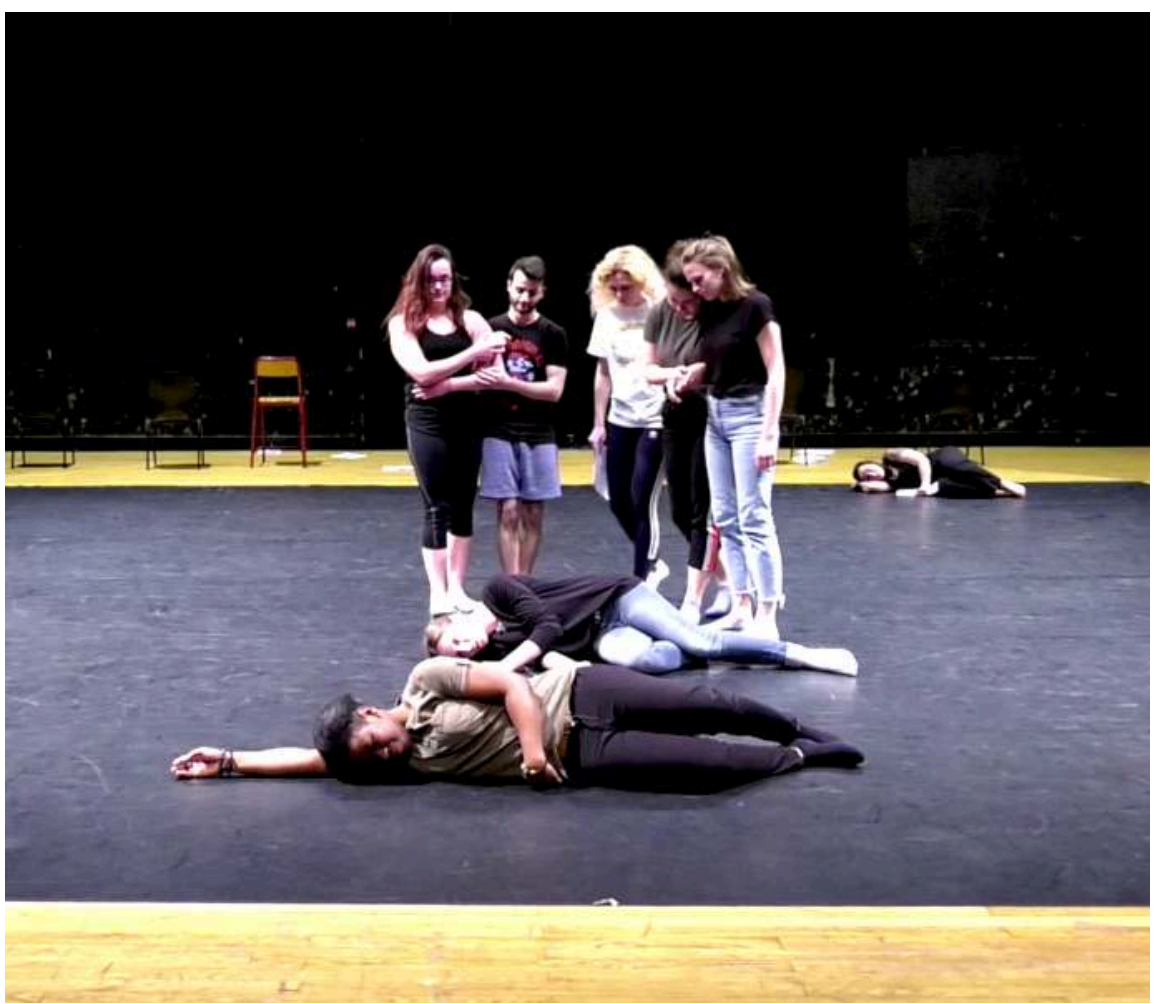

"Percival is dead. His horse stumbled.

He was thrown. This is the fact." (Act 2, scene 2)

They must however keep all the "poetic interludes" in place, and preserve the balance between the characters and the chorus. Woolf herself used a tight structural pattern to guide her readers amidst the complexity of mental states and social situations in the novel. In similar fashion, a very tight structure was used in the script to guide viewers through the continuous stream of thoughts, impressions and assertions.

Table 2 


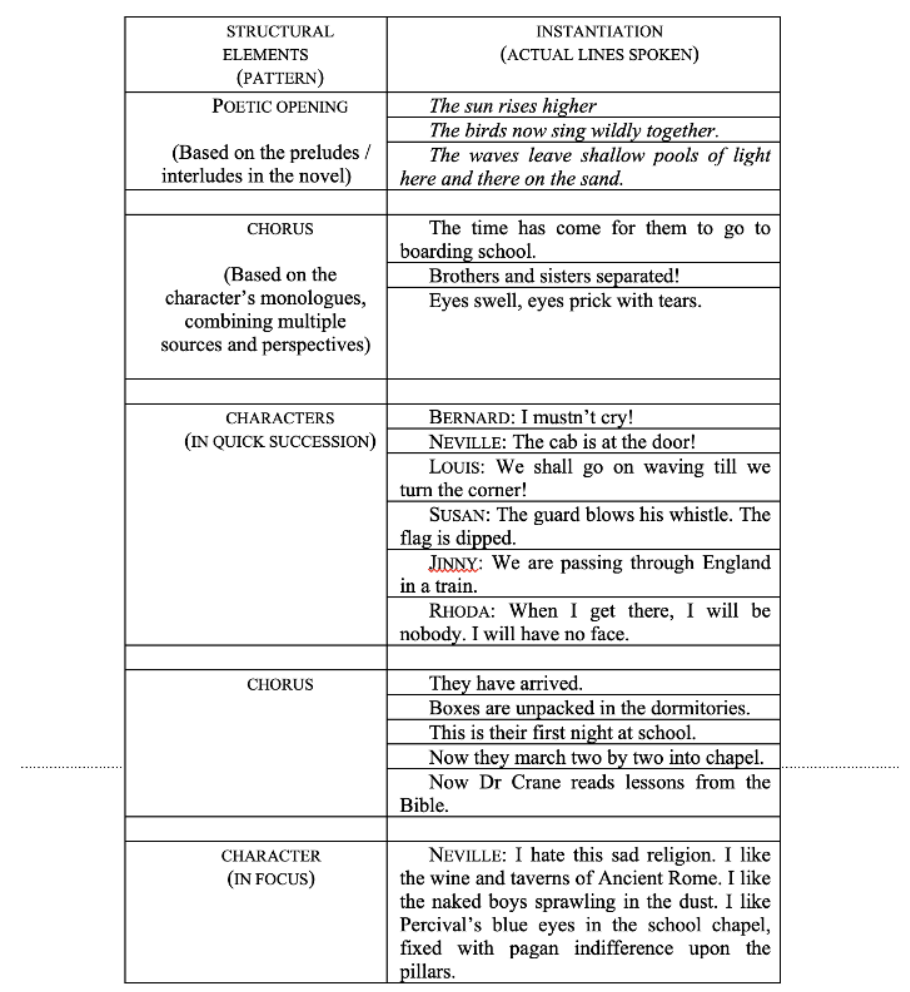

Basic template for a scene

(Act 1, scene 2)

Another reason for using a stable pattern is that recurrence and predictability are features that also apply to the cyclical movement of the waves, ceaselessly rising, breaking and receding. This movement pattern was used for the presentation of the scenes and tableaux as a continuous flux. The instructions given were the following: "while the first group performs a scene, the next two (in the sequence) watch from the wings. The rest of the students sit in the house, as would ordinary spectators. Once a scene or tableau is over, the tide comes in: the groups that have been waiting in the wings burst onto the stage, closing over the actors. A strong current is created. Within seconds, the tide goes out again. All the actors are driven out, except those scheduled to perform next, who take the stage. The students who are done with their piece leave the wings and take their seats among the audience. Another group rises and gets into position in the wings. And so on." 
Figure 15

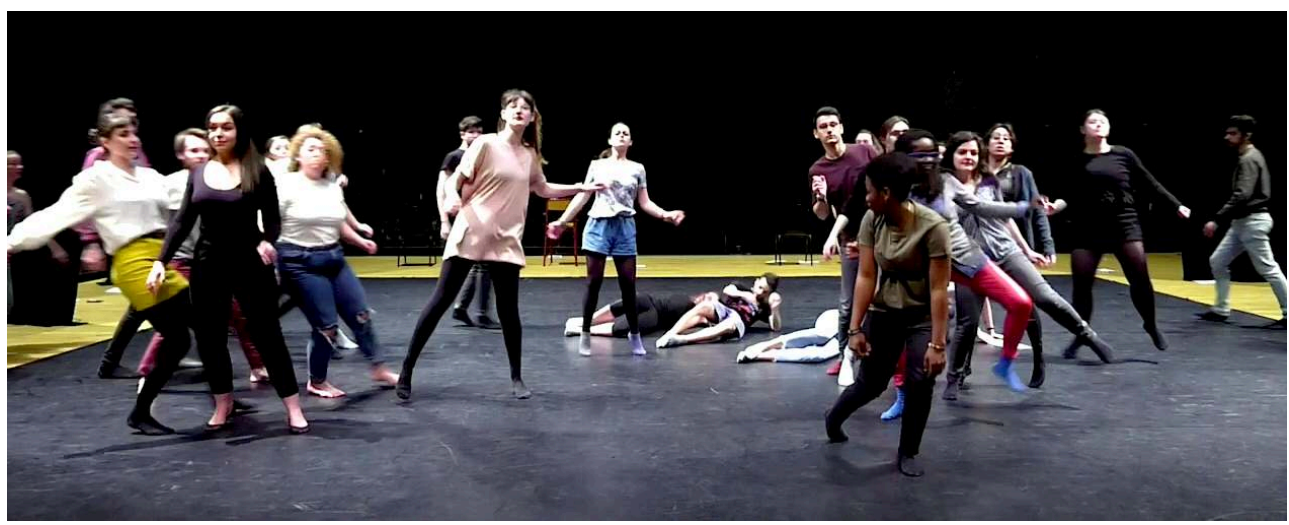

The scene is over: the waves break and "wash away" the actors

44 During the last workshop, a "grand finale" was staged. Students ran through all the scenes again, using the "tidal system" with fluidity. After the Epilogue, they congregated one last time in the middle of the stage, spaced themselves out and reestablished the initial soundscape for the ocean. They worked out a decrescendo, and then fell into a brief moment of silence. It was finished, it was done.

\subsection{Final performance at Teatro Civico, Vercelli, Italy (TILLIT 2019, June 5-6 2019)}

4515 students, among the 38 who had attended the workshops, travelled to Italy ${ }^{14}$ and took part in the fifteenth edition of TILLIT (Teatro in Lingua, Lingua in Teatro) - an international student festival hosted by Università del Piemonte Orientale, Vercelli (dir. Marco Pustianaz, ass. Michaela Reinhardt). The touring company was named Choreographers of Speech.

Figure 16

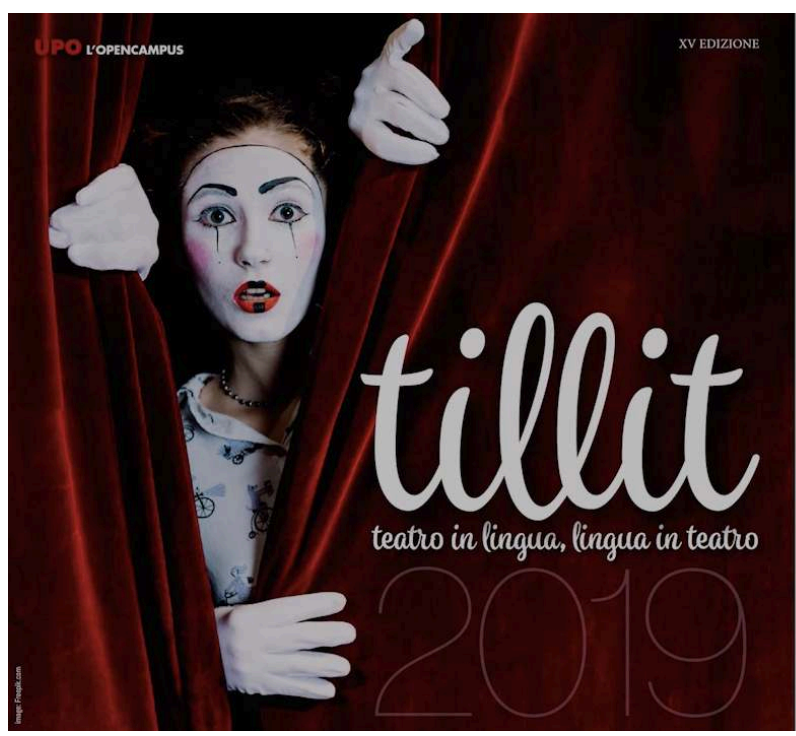

\section{5 giugno}

Vercelli, Teatro Civico

\section{CHOREOGRAPHERS OF SPEECH}

(Université Bordeaux-Montaigne)

"Breaking Virginia's Waves"

Adatt. Virginia Woolf

Coordinatore Jean-Rémi Lapaire

Registi Julie Cabaret,

Sarah Caillaud,

Célestine Fisse,

Alexandre Gauzentes

Consulente teatrale Oliver Borowski

Coreografia Melissa Blanc

UPO 
The four drama students in the group - Julie Cabaret, Sarah Caillaud, Célestine Fisse, Alexandre Gauzentes - offered to revise the production. Building on Melissa and Oliver's work, they designed a 34-minute version of the piece that was performed on the historic palco (stage) of Teatro Civico, Vercelli.

Figure 17

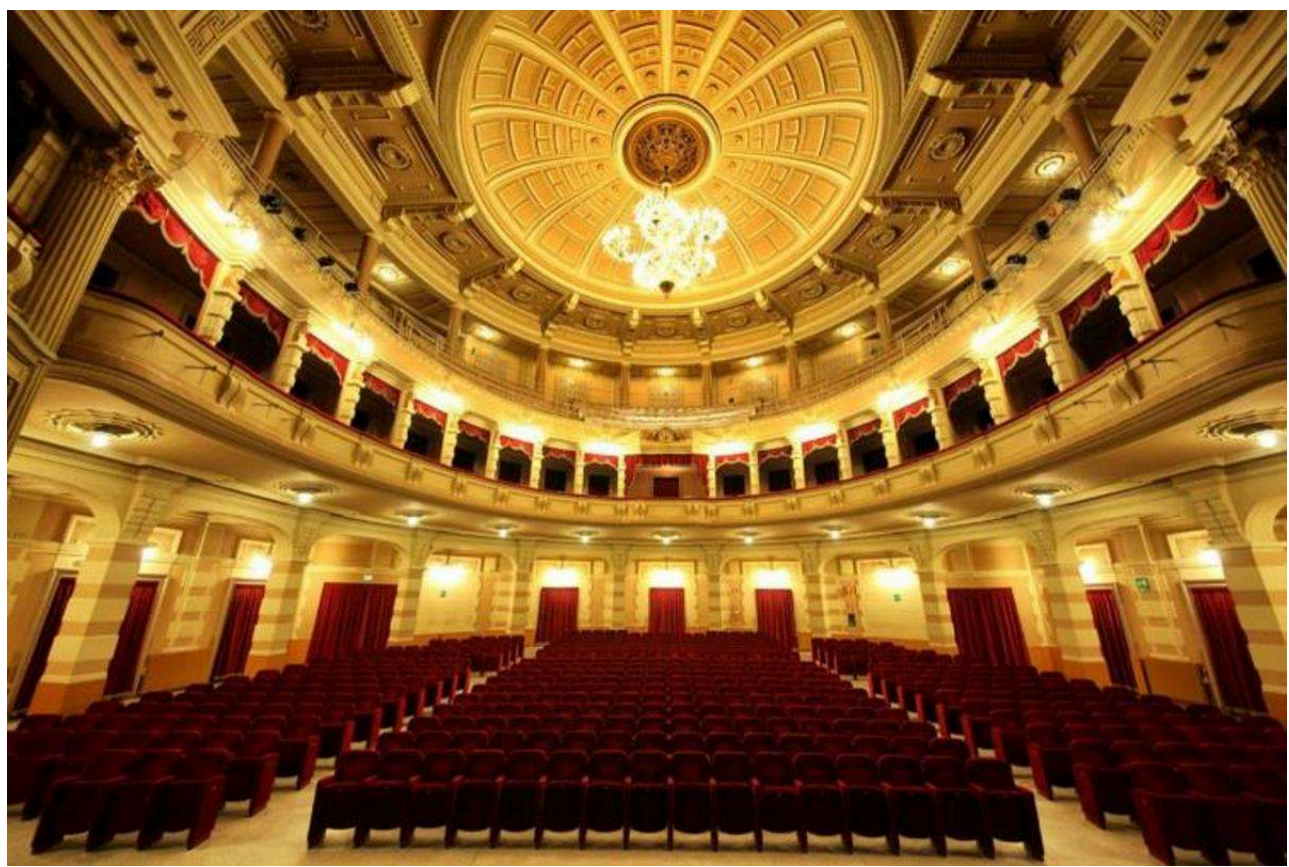

Teatro Civico, Vercelli (Piemonte)

The Prologue was kept in its original form but the successive scenes and tableaux were considerably refined and improved. A new character was created: the "poet" whose job was to recite the preludes and occasionally mix with the chorus. The centrality of Percival - a hollow but obsessive figure in the novel - was made explicit in the play. In this new production, he was in charge of introducing the acts, using bilingual signs in English and Italian. Percival's sensuous appeal to both women and men made him eligible for queer aesthetics. Below is a visual testimony of the public performance given in Vercelli on June $5^{\text {th }} 2019$ - a remarkable achievement and a true "moment of being." 
Figure 18

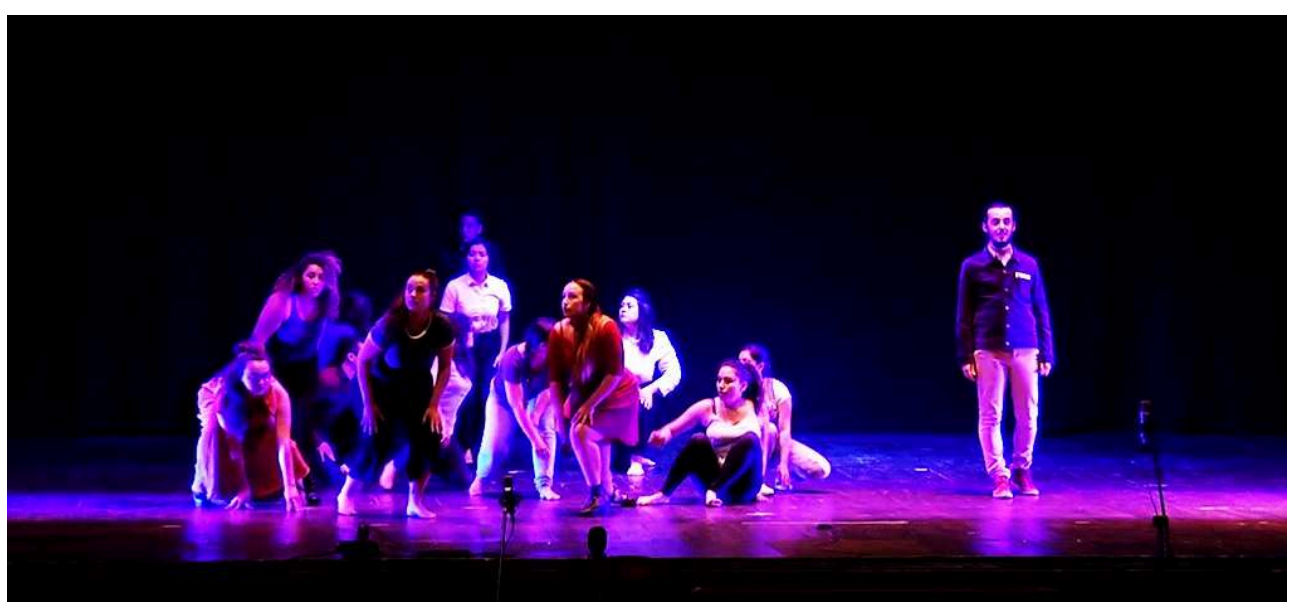

Bernard: "I am not one person, I am many people" (Prologue)

Figure 19

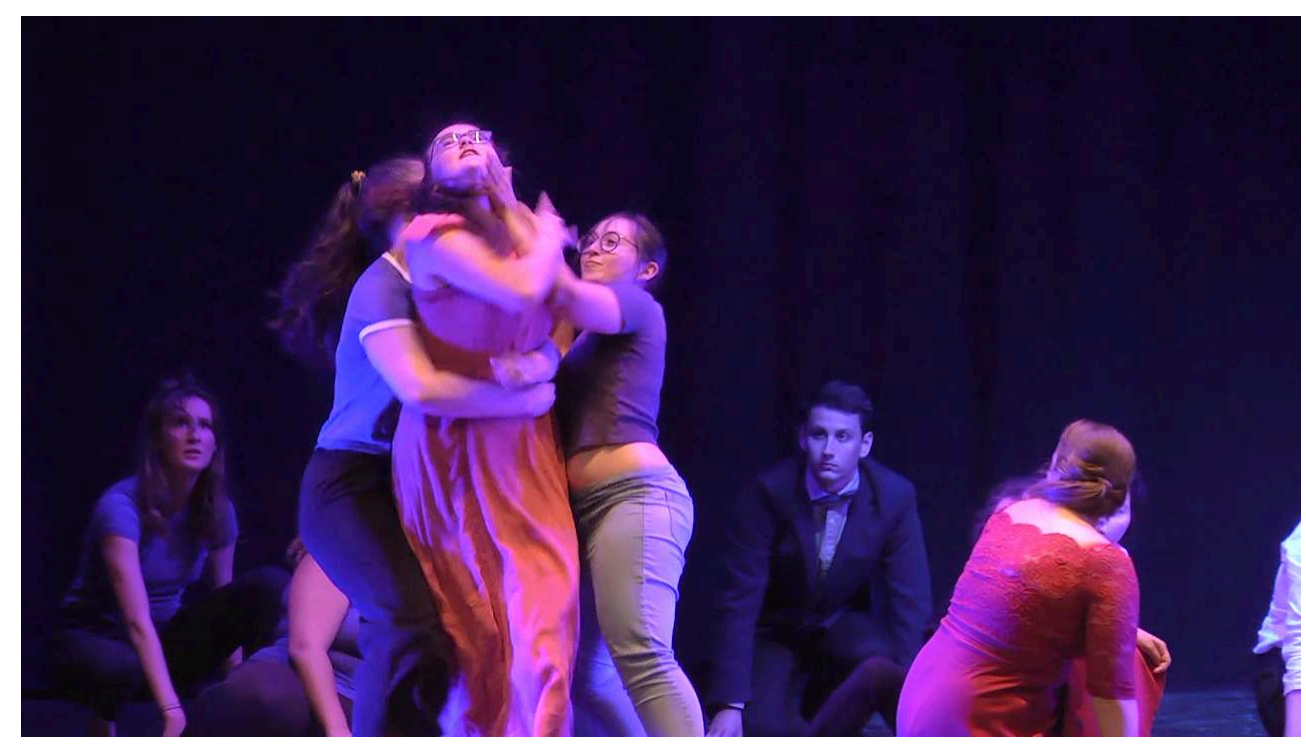

Rhoda: "Who and what are these unknown people? What are stories?" (Prologue) 
Figure 20

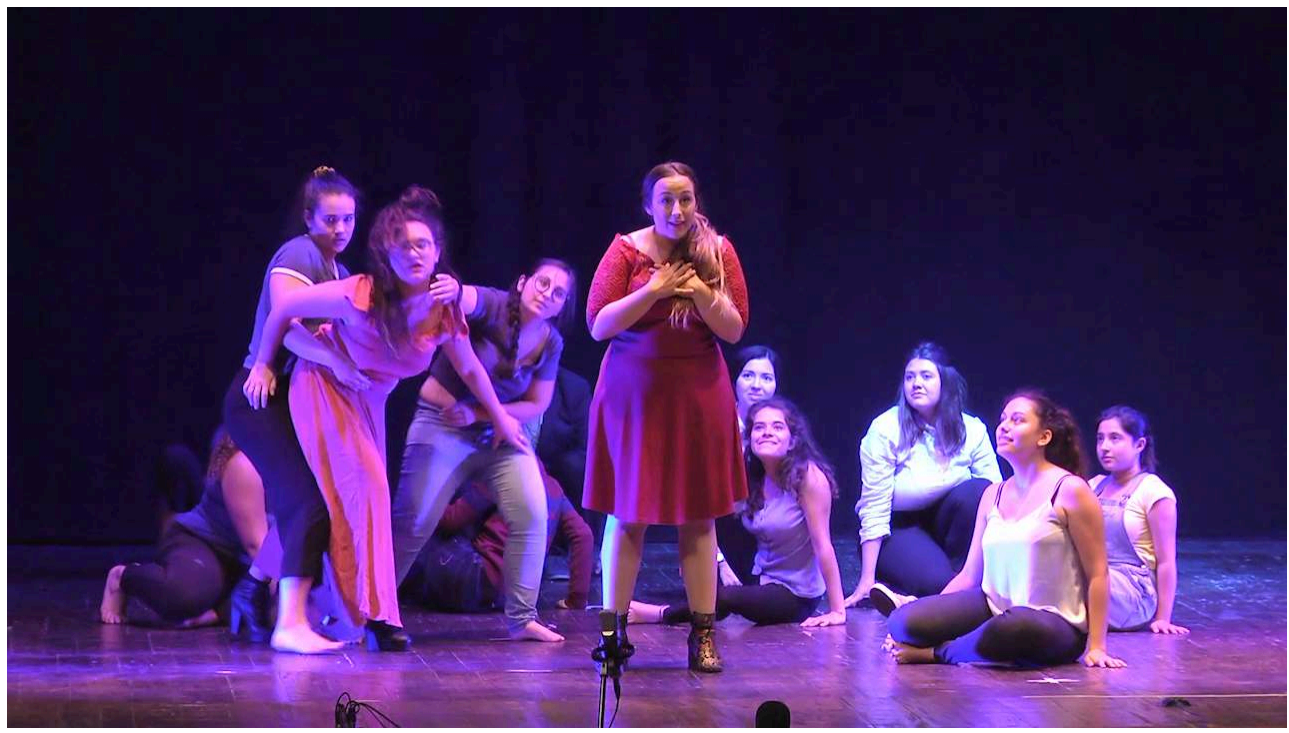

Jinny: "There is always a story. I am a story!" (Prologue)

\section{Figure 21}

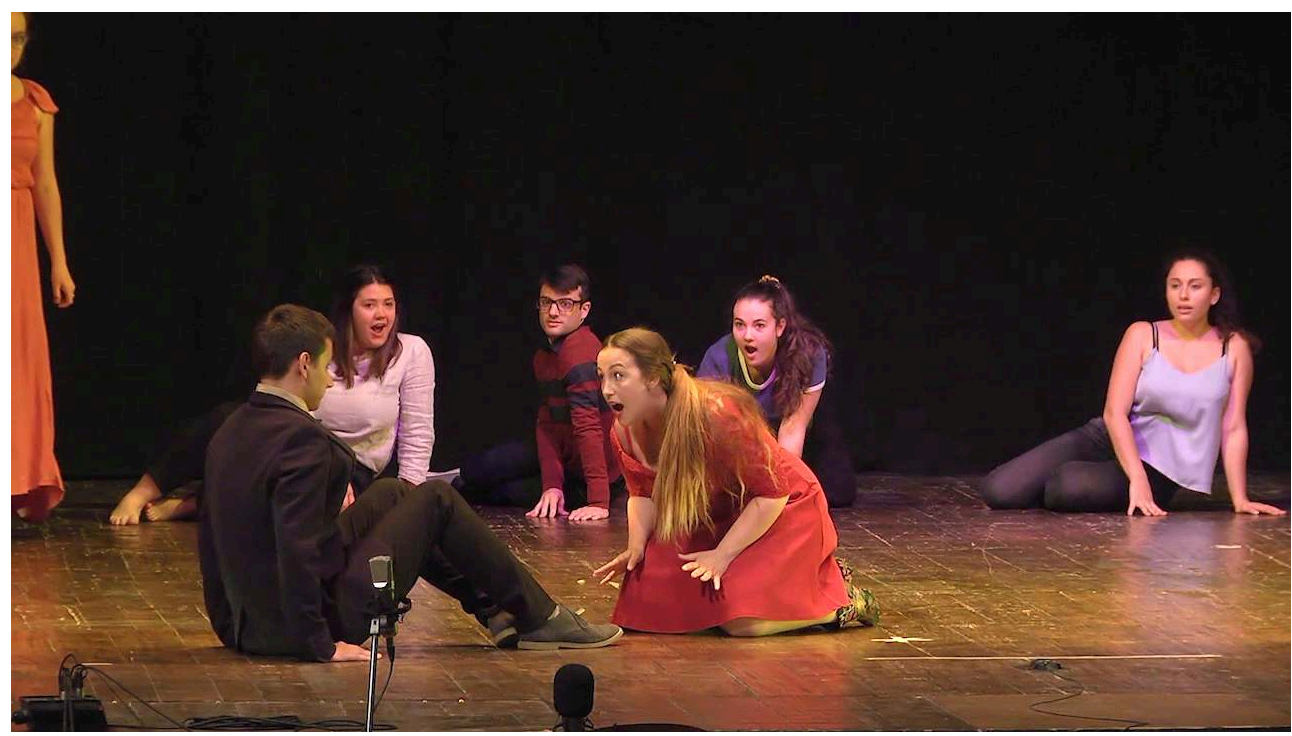

Jinny: "I saw you, green as a bush and lying very still.

I cried. 'Is he dead?"' (Act 1, scene 1) 
Figure 22

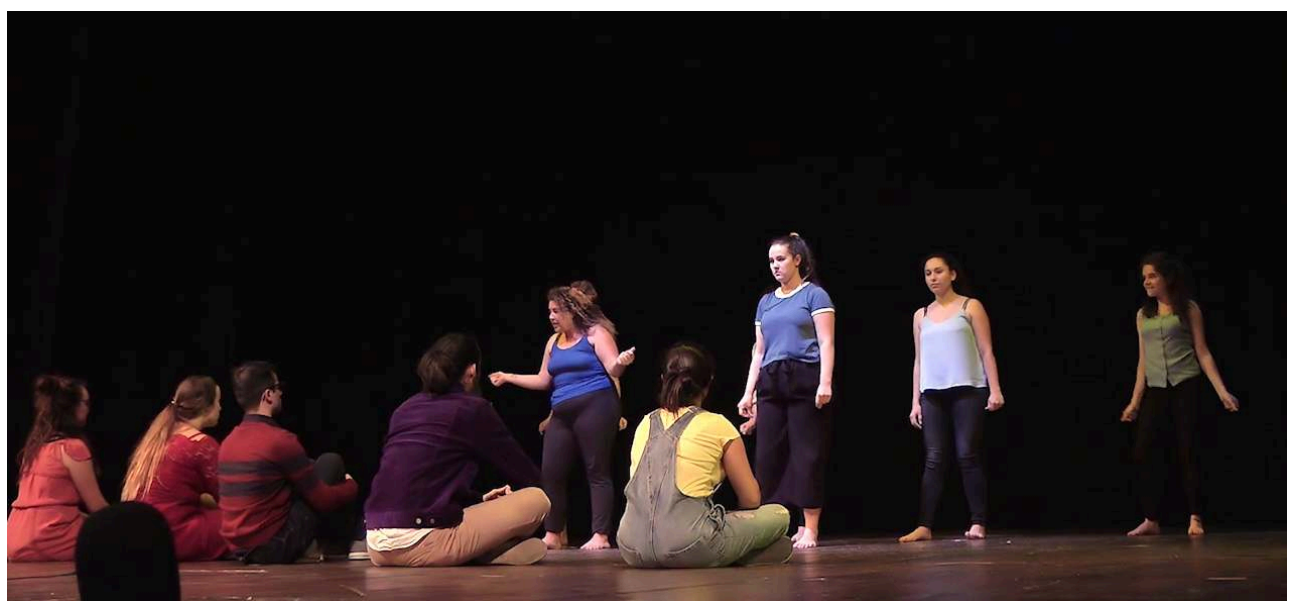

Chorus: "Now is the time for Miss Hudson's lessons

The clock is ticking in the classroom - tick, tick, tick." (Act 1, scene 1)

Figure 23

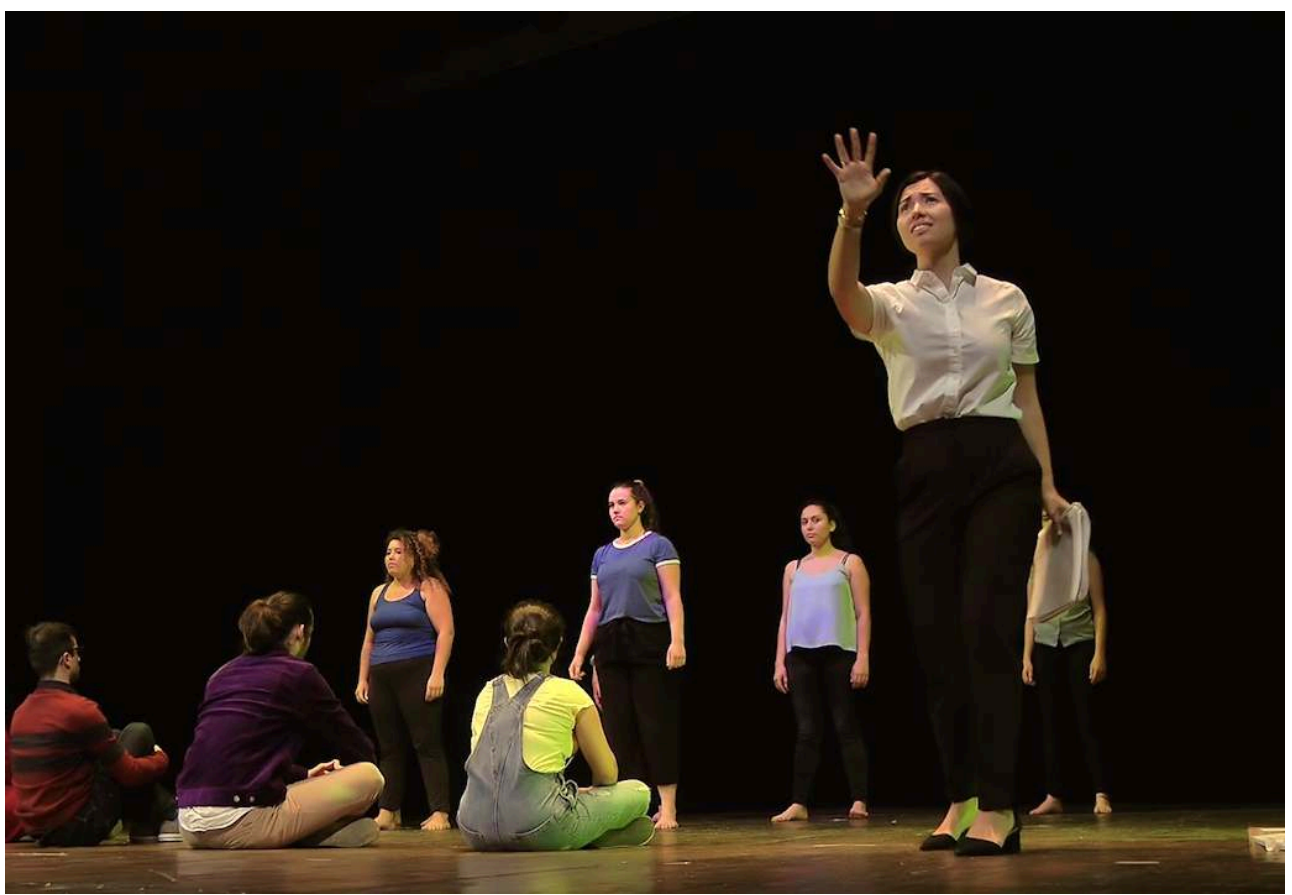

The Poet: The sun rises higher.

The birds now sing wildly together. (Prelude to Act 1, scene 2 ) 
Figure 24

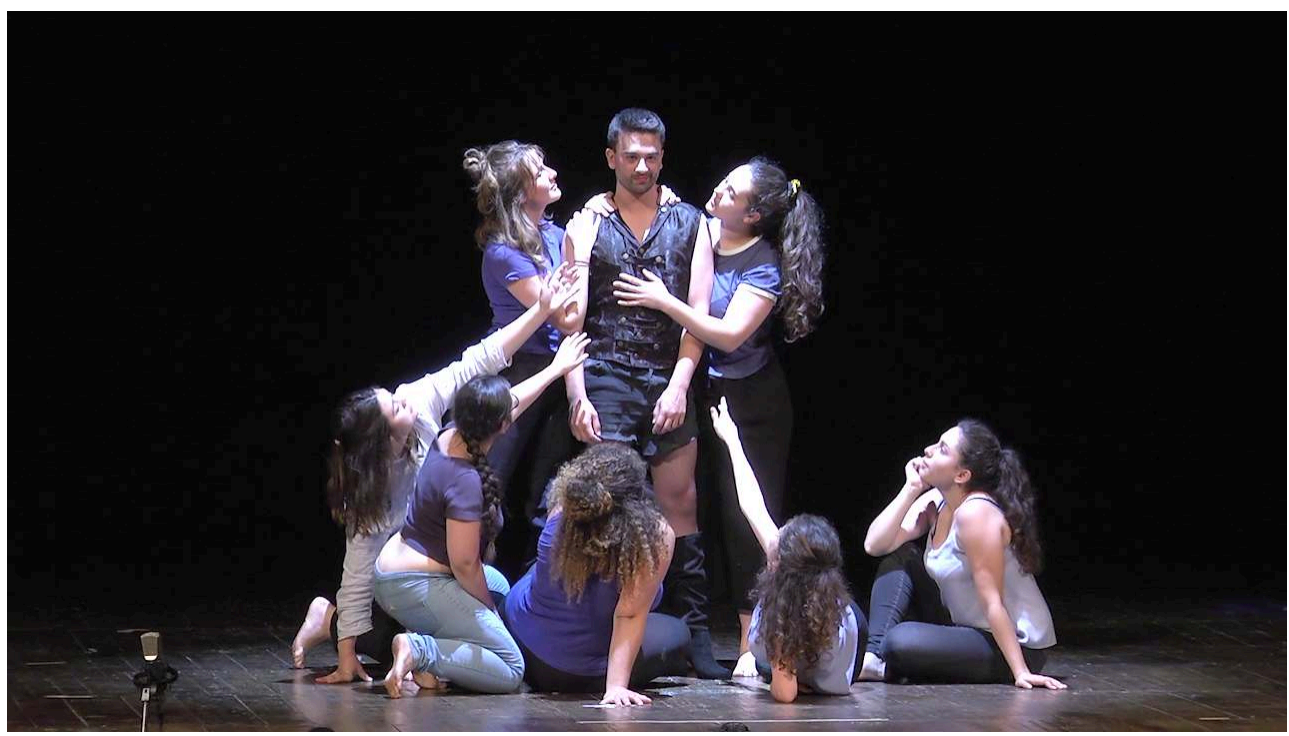

Chorus: «Percival's movements are remarkable. (Act 1, scene 2)

He has the kind of beauty that one falls in love with for a lifetime, hopelessly!"

\section{Figure 25}

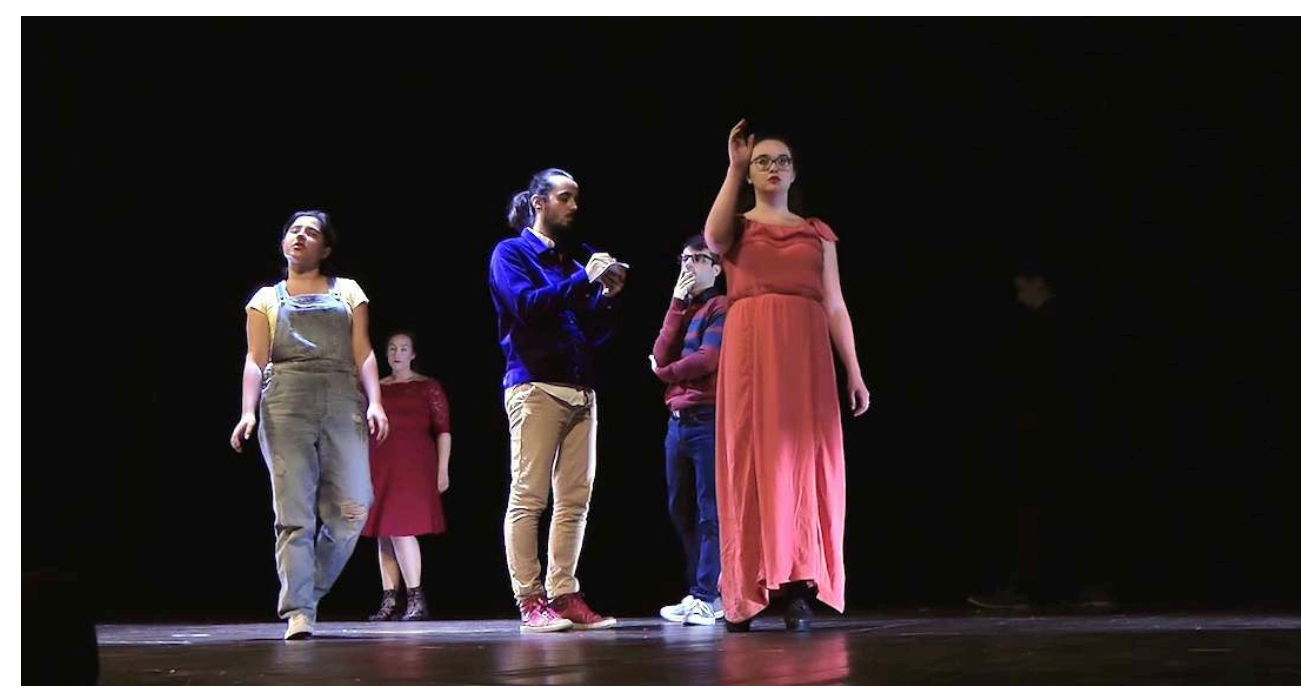

Susan: "I miss my home, I miss my father.

I will never send my children to boarding school." Never! (Act 1, scene 2) 
Figure 26

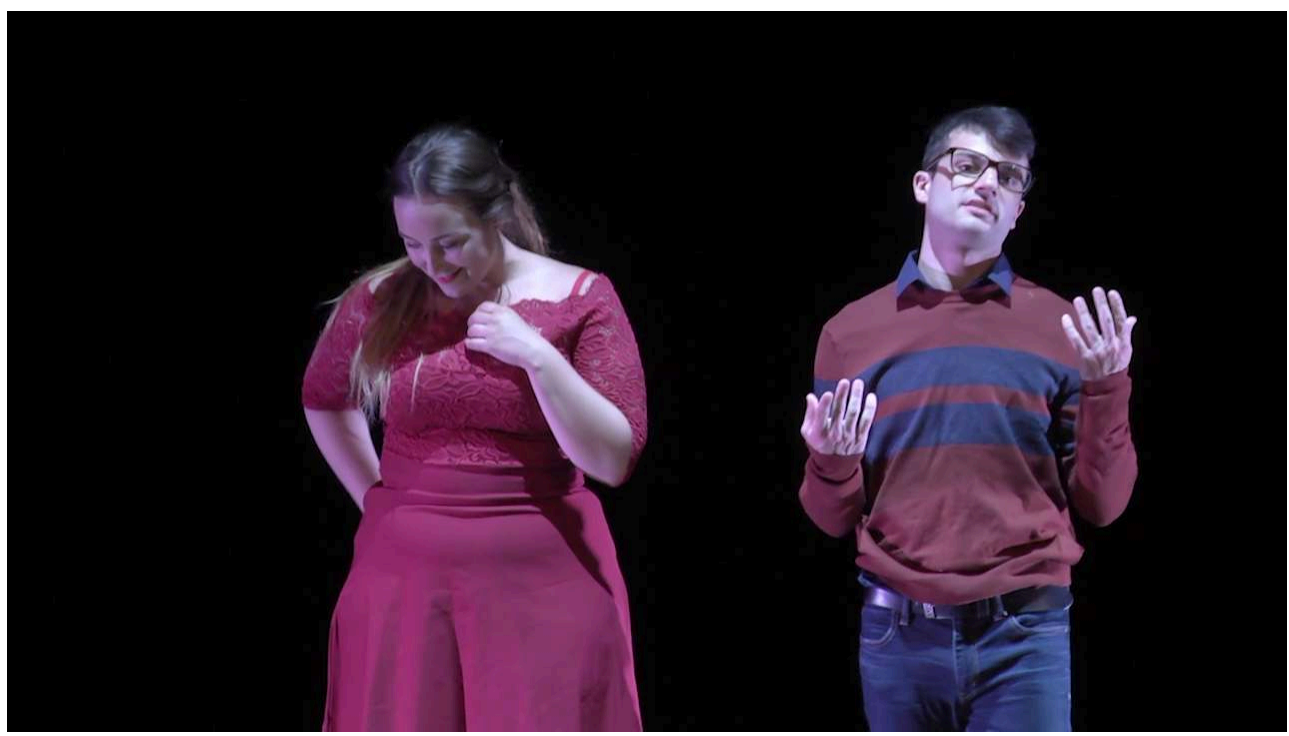

Neville: "Percival will forget me." (Act 1, scene 2)

\section{Figure 27}

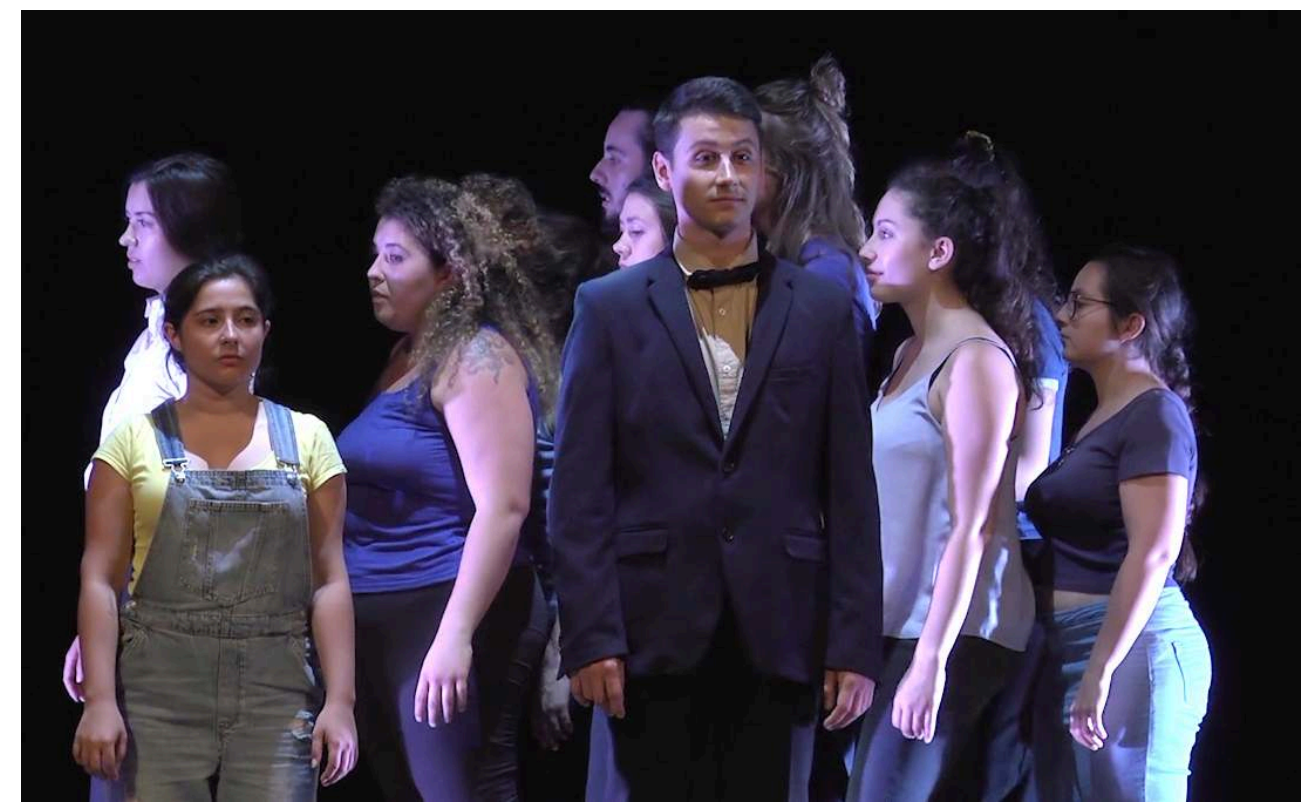

Louis: "This is the real world! I have become an average Englishman.

I am an average clerk, poring over commercial documents." (Act 1, scene 3)

Figure 28 


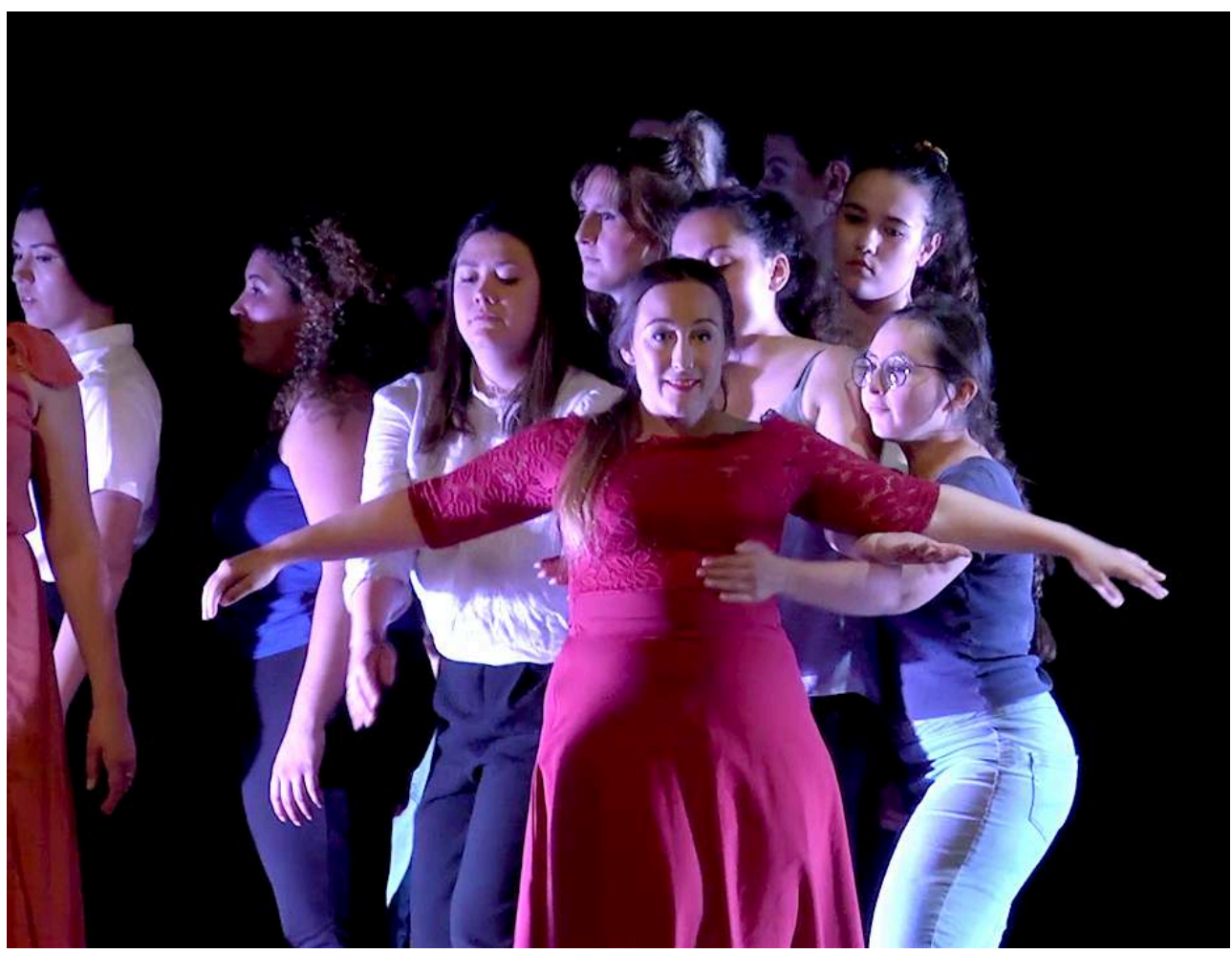

Jinny: "This is London! This is my calling! This is my world!

I glance, I peep, I powder. I open and shut my body at my will." (Act 1, scene 3)

Figure 29

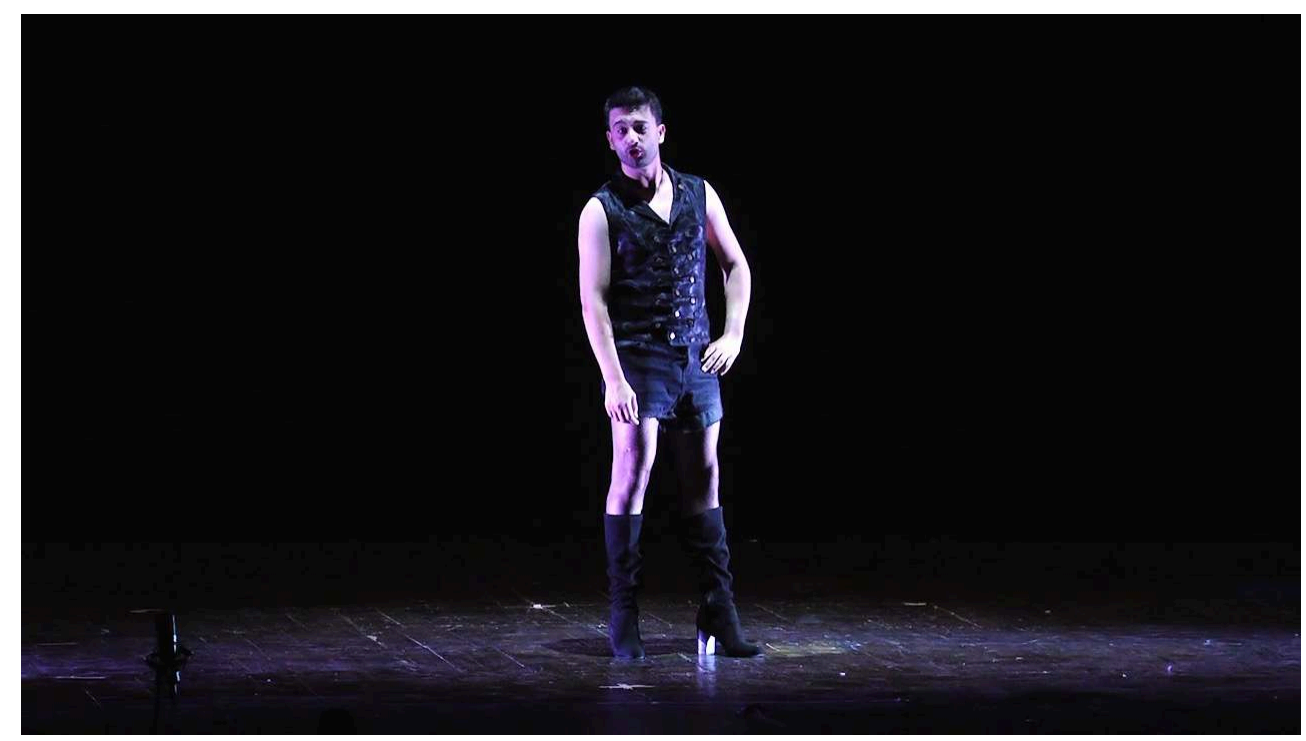

Percival introduces Act 2: "Noon - Mezzogiorno" 
Figure 30

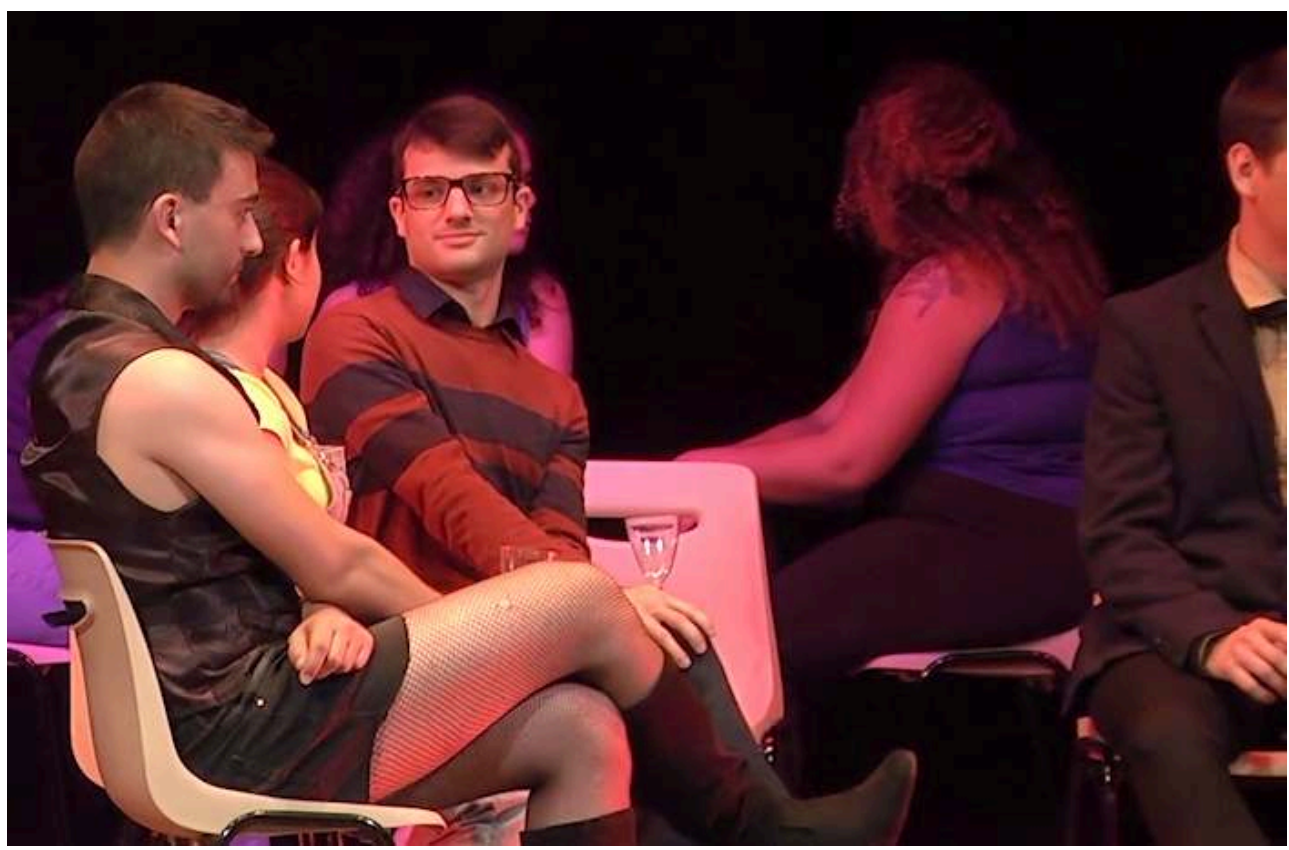

Neville: "Percival is going. I came here to sit by him. But I shall never have what I want." (Act 2, scene 1)

Figure 31

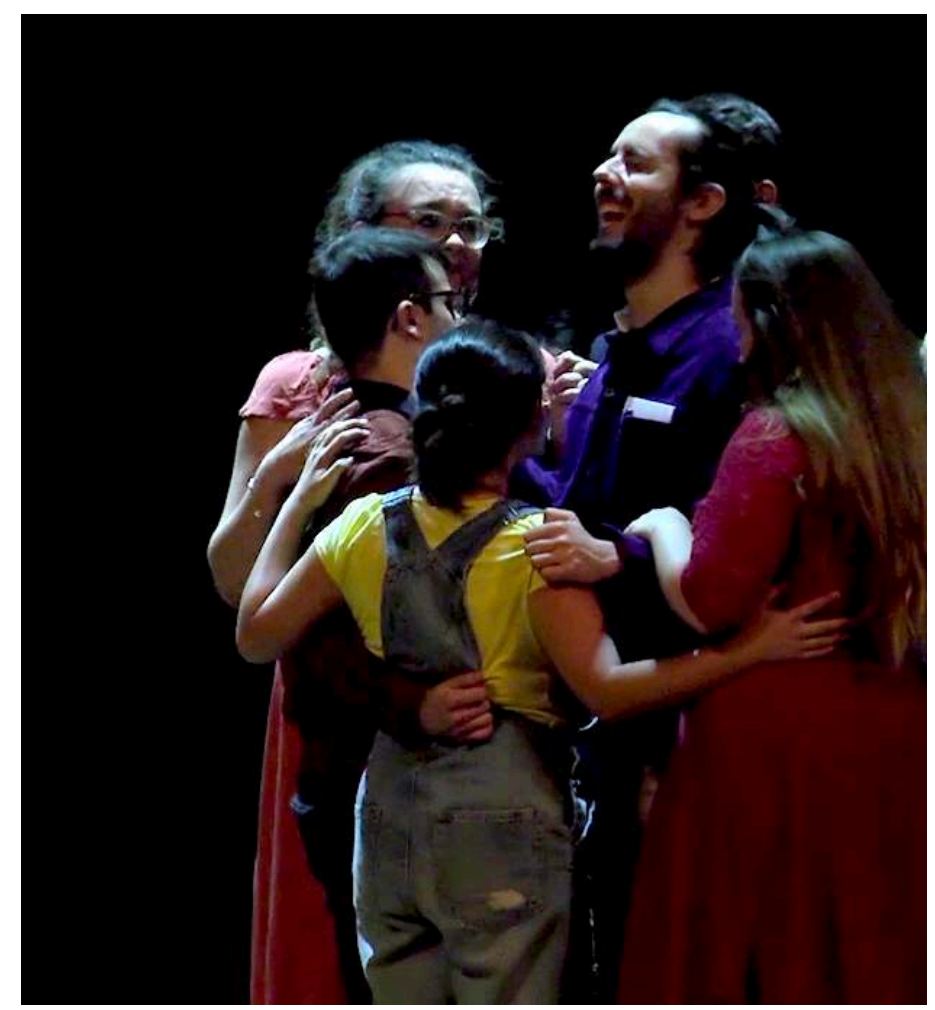

Bernard: "My son is born, and Percival is dead!" (Act 2, scene 2) 
Figure 32

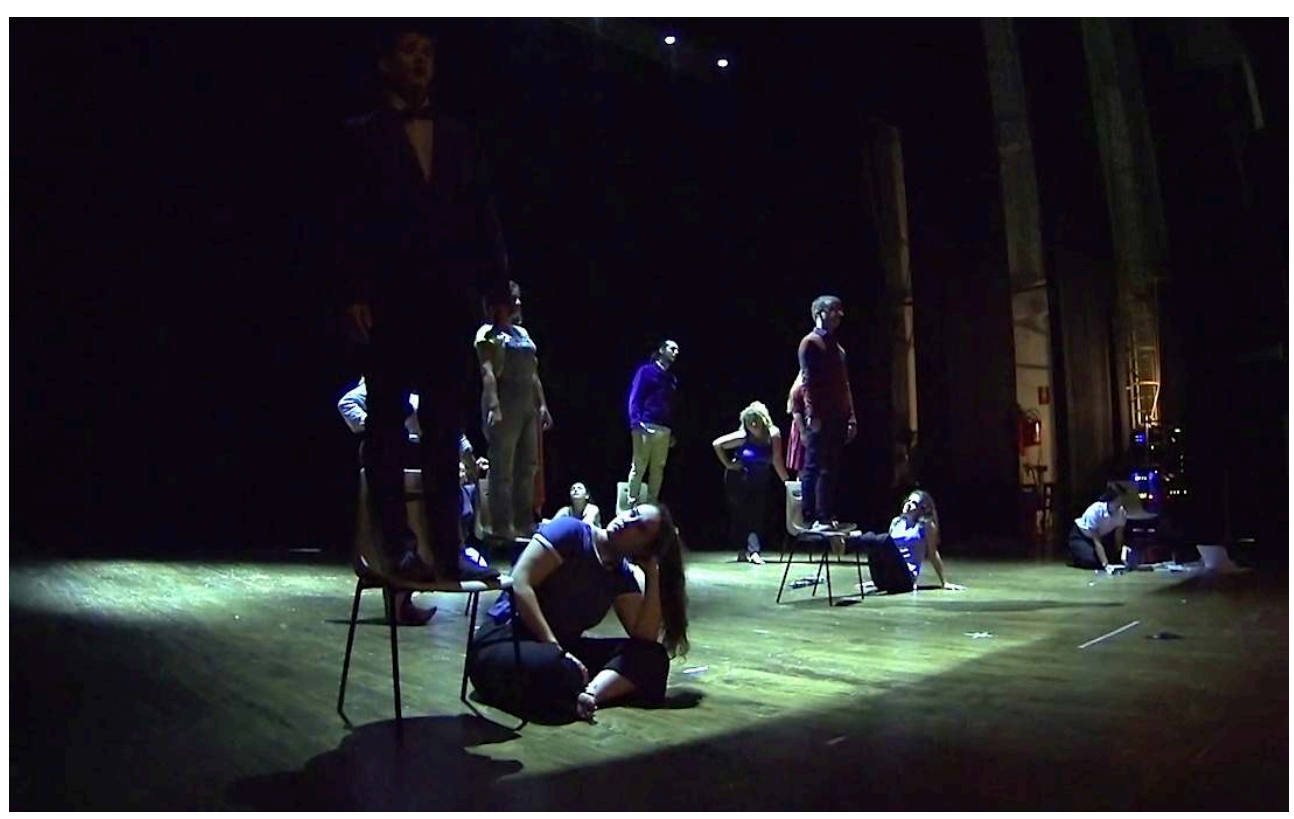

Bernard: "How does light return to the world after the eclipse of the sun? Miraculously: loveliness returns as one looks." (Act 2, scene 3)

\section{Figure 33}

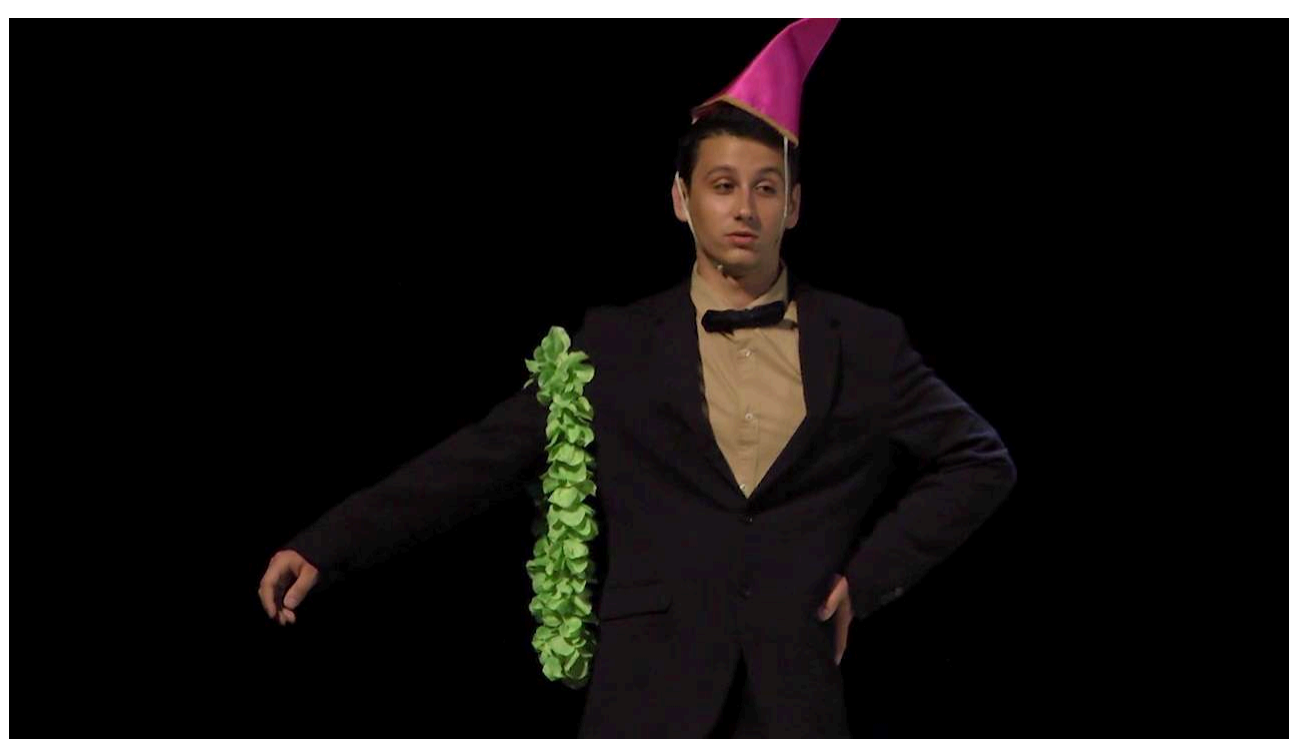

Louis: "Percival died, Rhoda left me." (Act 3, scene 1) 
Figure 34

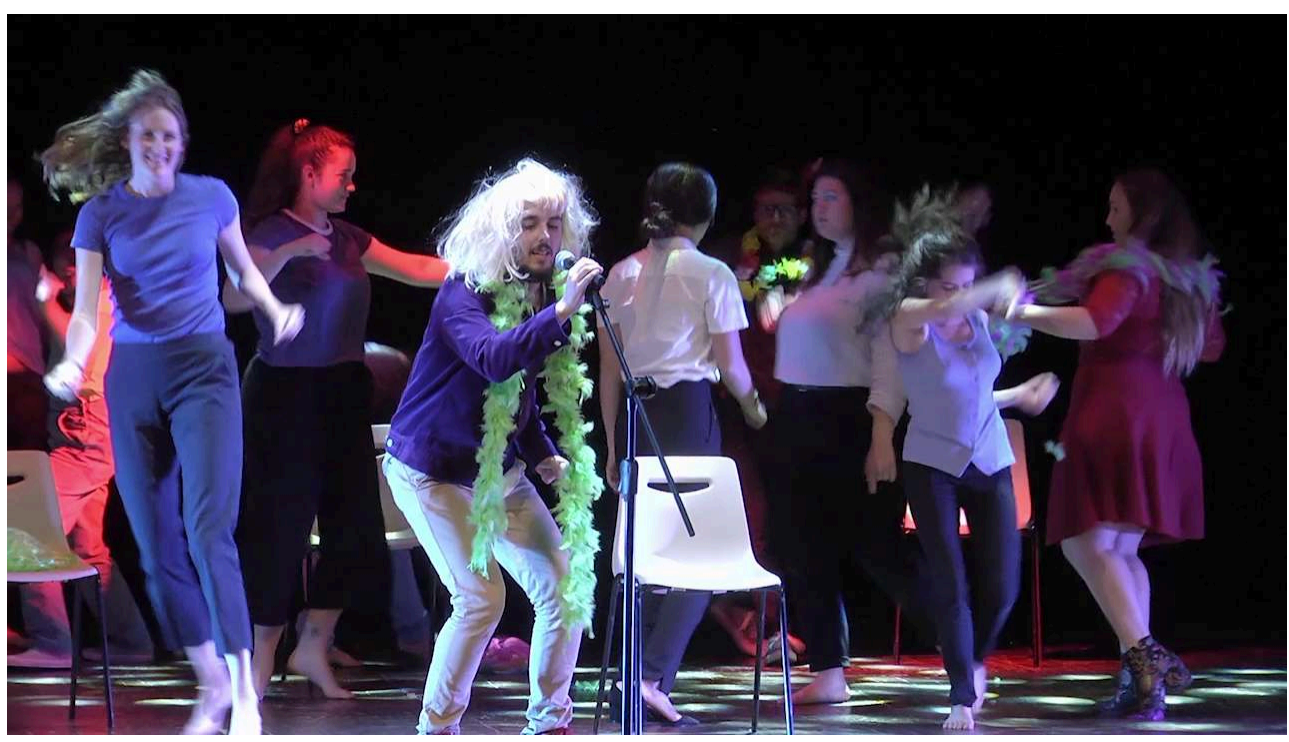

Bernard: "Hampton Court. This is the Inn.

This is our last meeting place." (Act 3, scene 2)

\section{Figure 35}

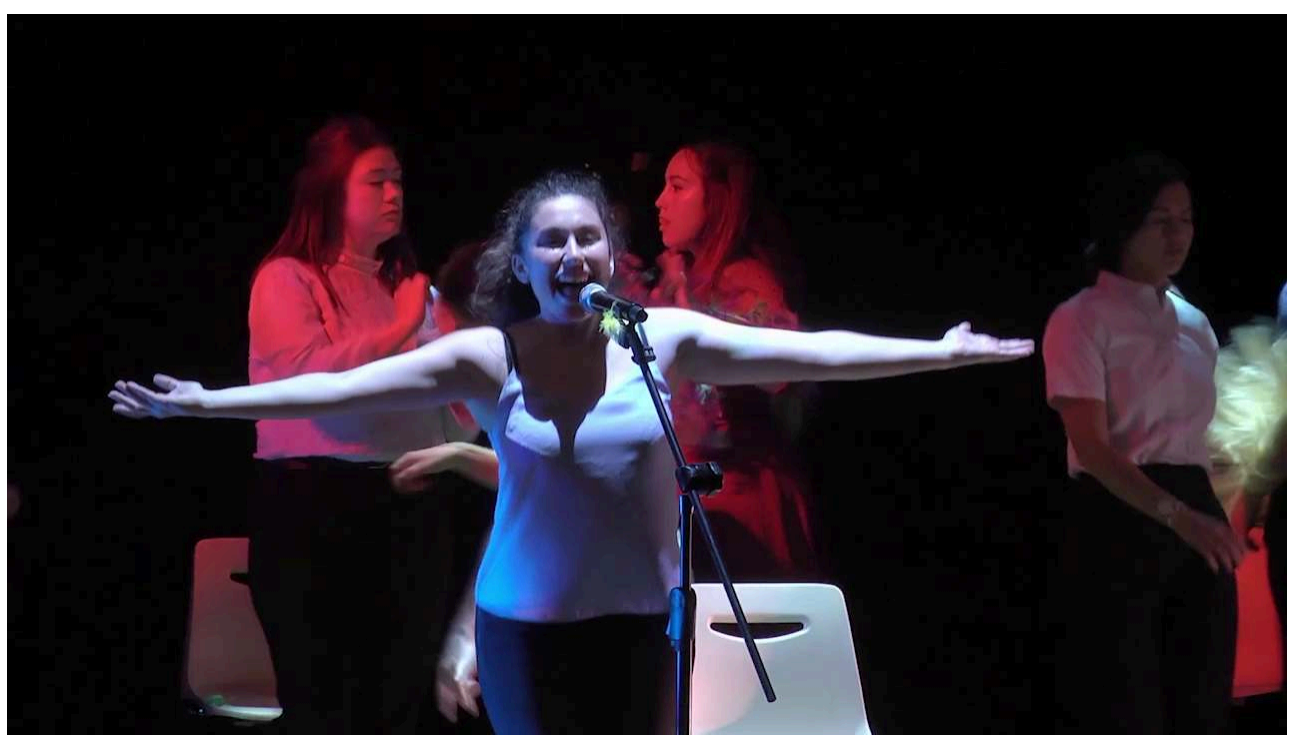

Chorus: "It was different once.

They could have been anything!" (Act 3, scene 2) 
Figure 36

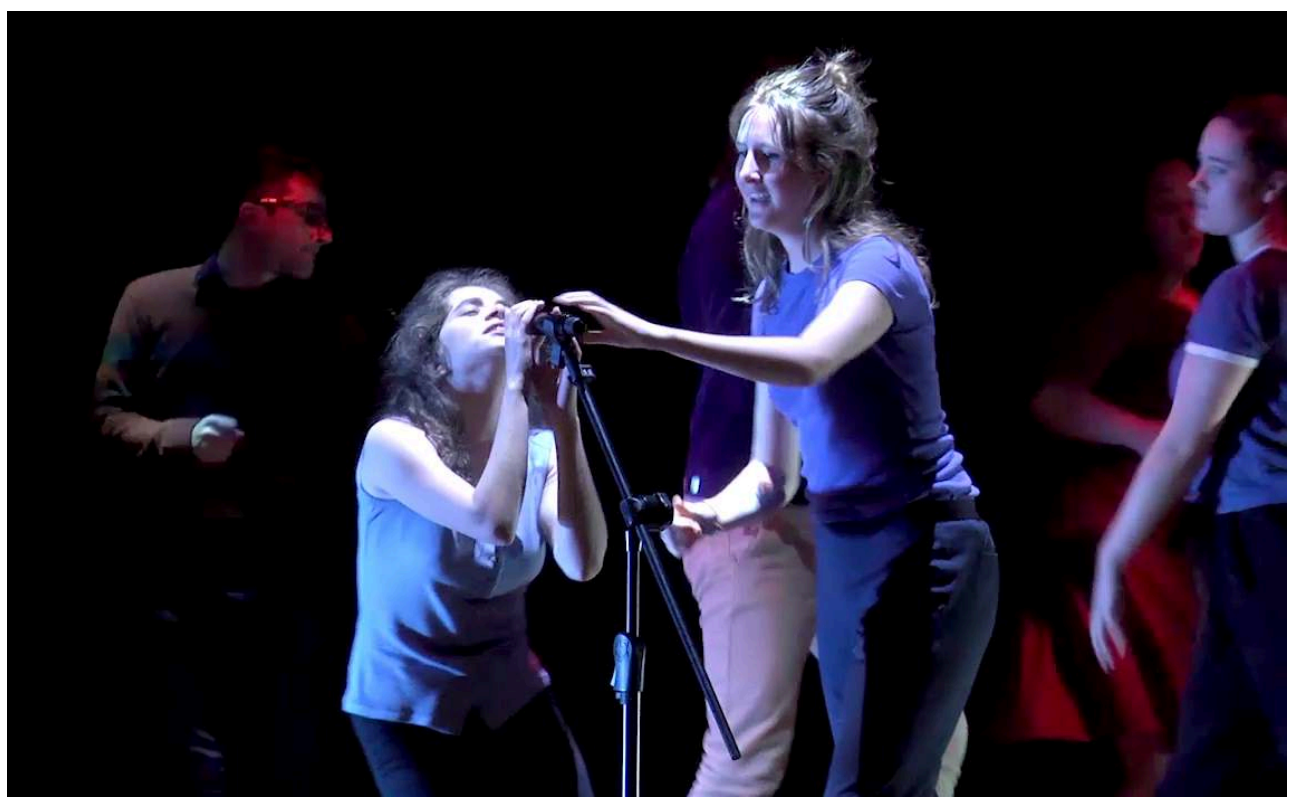

Chorus: "We have triumphed"! "No, we have failed!"

"Love, love!" "My wasted life!" they say.

Figure 37

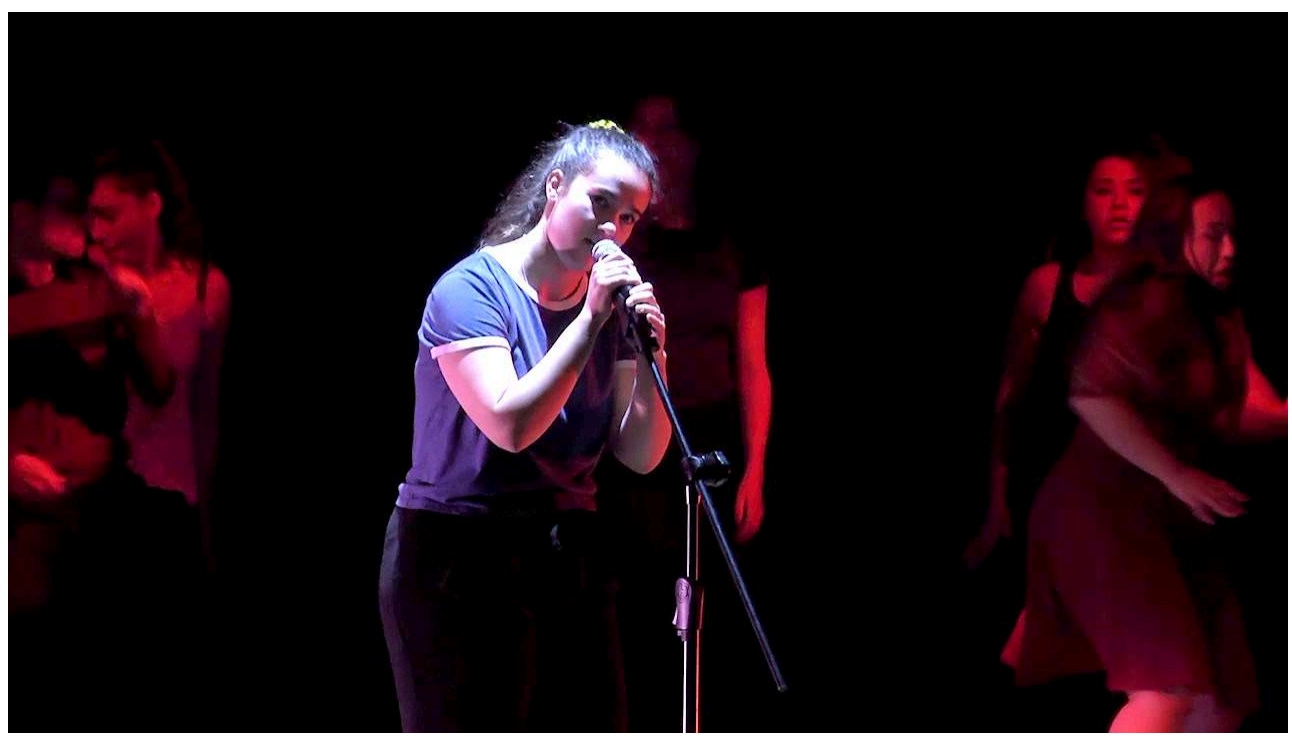

Chorus: "Now the waves will spread between them.

They will float for a moment - and then they will sink." 
Figure 38

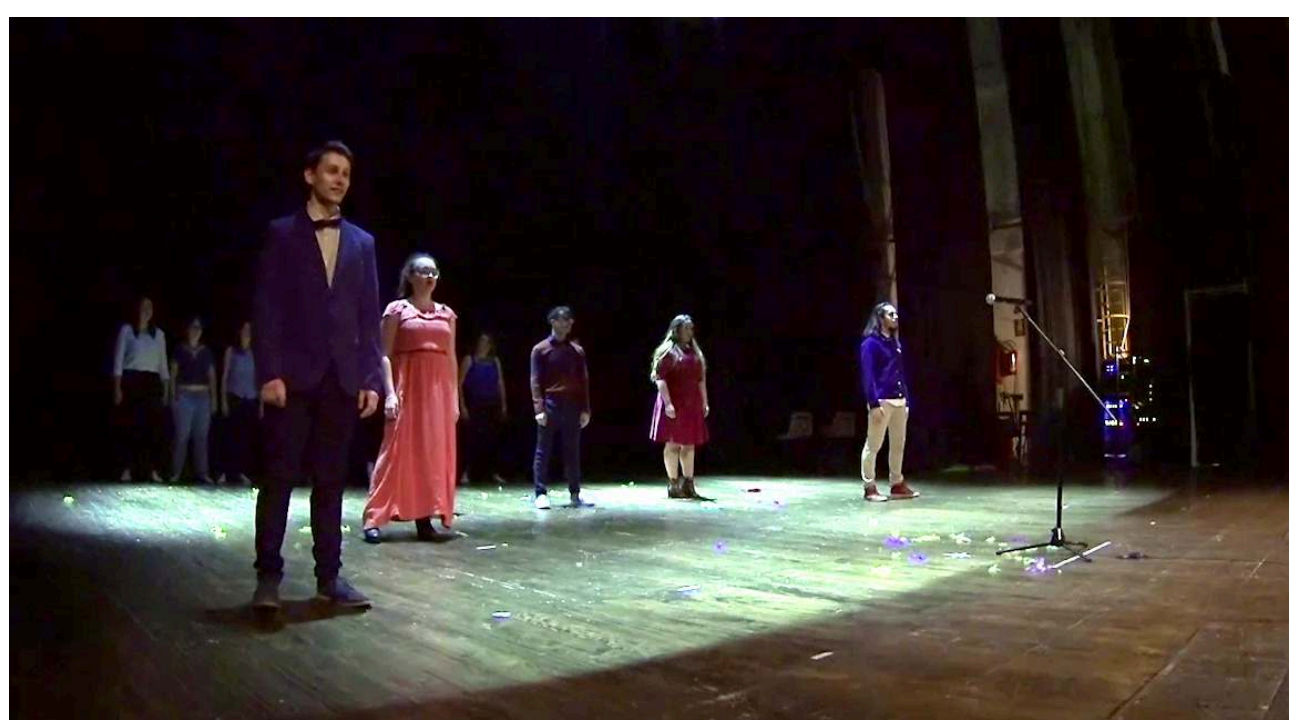

Louis: "Life is pleasant, life is good" (Epilogue)

Figure 39

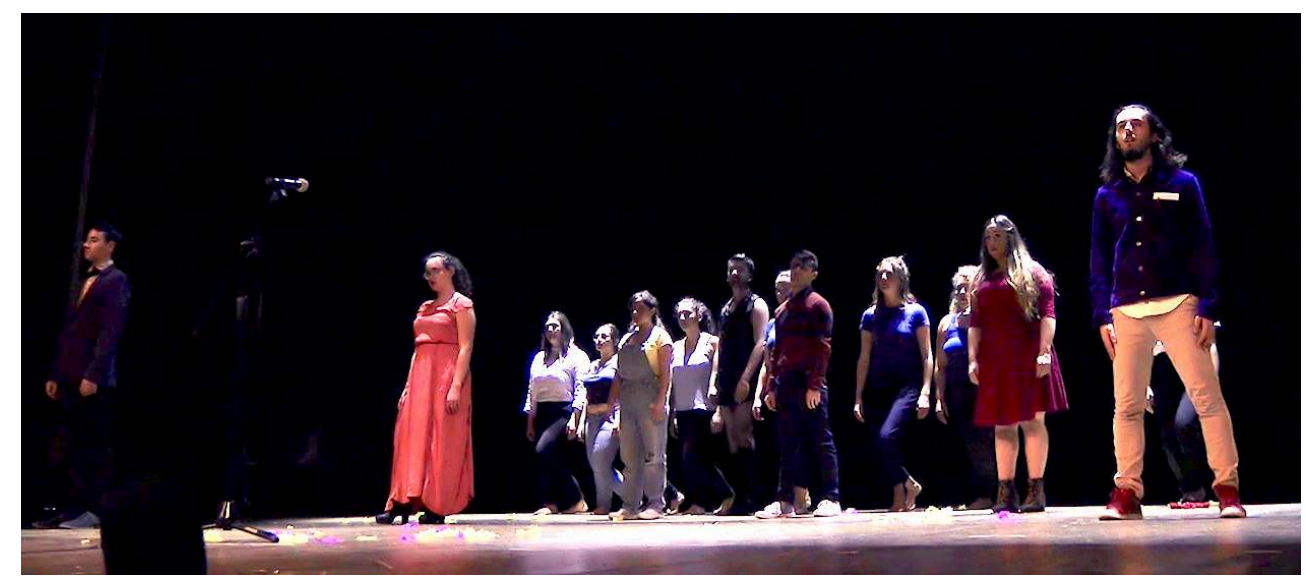

Percival: "I am Percival. I will ride my horse

and fling myself against death, unvanquished, unyielding!" (Epilogue) 
Figure 40

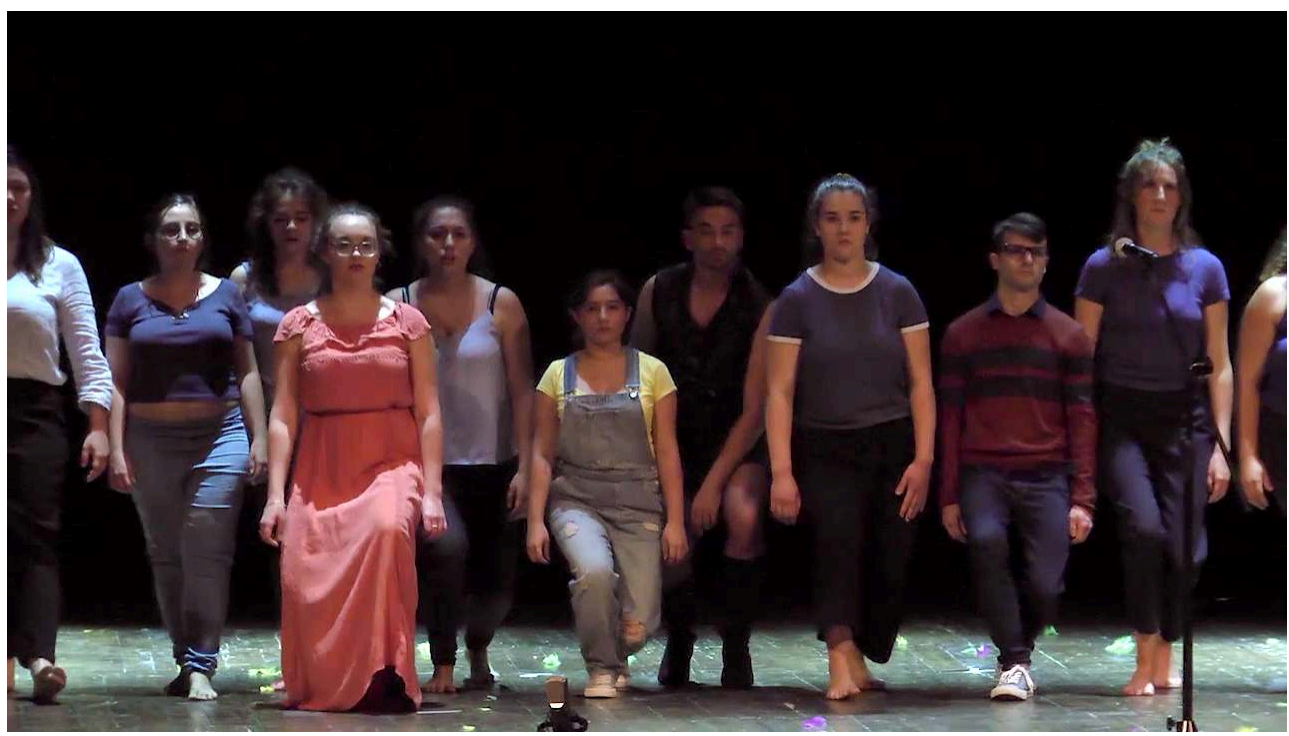

Chorus: "We float, we are swept on by the torrent of things" (Epilogue)

Figure 41

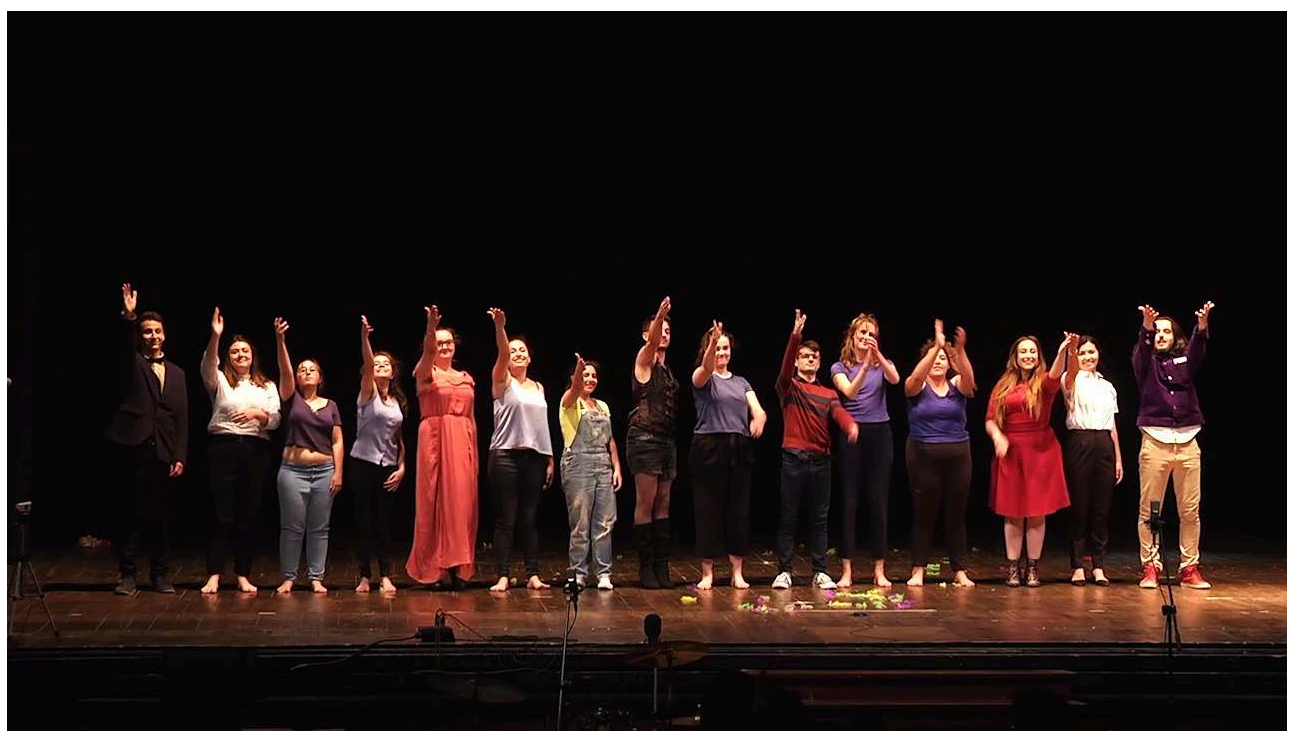

Recognizing the stage manager and lightening designer at the end of the curtain call

\section{Dance and theatre script}

The script (2684 word, 8 pages) is a 3.4\% reduction of Woolf's novel (77 480 words, 225 pages). The main challenge was to determine what constituted the "bare essentials" of Woolf's narrative, and compile a script that would "work" for the stage and inspire students. Abridgement and compression force the scriptwriter to make radical interpretive choices, to decide what is essential and what is not, and to produce an inspiring text for artists and intersemiotic mediators. 
Although I had planned to involve the students in the creative re-writing process to the very end, I was forced to complete the work myself for want of time. I succeeded in preserving most of the vocabulary and imagery used in The Waves although I did slightly alter the grammar and elaborate syntax at times. Wherever possible, I adopted a direct "cutting out" technique, similar to the one used in postproduction when editing a film or video. I felt it was both the easiest and most honest way to preserve the authenticity of recycled material. Sometimes too, I combined "clipping" with a "reordering of constituents." I also "stole" lines from the protagonists and reassigned them to the chorus (and in one isolated instance to a dead character-Percival).

Table 3

\begin{tabular}{|c|c|}
\hline $\begin{array}{l}\text { ORIGINAL SENTENCE } \\
\text { (SOURCE NARRATIVE) }\end{array}$ & 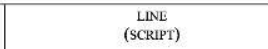 \\
\hline $\begin{array}{l}\text { (Jinny) Faces recur, faces and faces- } \\
\text { they press their beauty to the walls of my } \\
\text { bubble (197) }\end{array}$ & $\begin{array}{l}\text { Josnx: Faces recur, faces and } \\
\text { faces. }\end{array}$ \\
\hline $\begin{array}{l}\text { (Bernard) How fast the stream flows } \\
\text { from January to December! We are } \\
\text { swept on by the toment things grown. so } \\
\text { faniliar that they cast no shadow. We } \\
\text { float, we float... (198) }\end{array}$ & $\begin{array}{l}\text { CHORUS: We float. We are swept } \\
\text { on by the torrent of things. }\end{array}$ \\
\hline $\begin{array}{l}\text { (Bemard) It is over, we are ended } \\
\text { But wait }- \text { I sat all night waiting - an } \\
\text { impulse again runs through us; we rise; } \\
\text { we toss back a mane of white spray; we } \\
\text { pound on the shore; we are not to be } \\
\text { confined. (205) } \\
\text { (Last interlude) The waves broke on } \\
\text { the shore. (228) }\end{array}$ & $\begin{array}{l}\text { CHoRus: We rise, we break, we } \\
\text { pound on the shore. }\end{array}$ \\
\hline $\begin{array}{l}\text { (Jinny) I am in the heart of life. But } \\
\text { look - there is my body in the looking } \\
\text { glass. How solitary, how shrunk, how } \\
\text { aged! I am no longer young. I am no } \\
\text { longer part of the procession (...) I am a } \\
\text { native of this world, I follow its banners } \\
\text { (..) Therefore } I \text { will power my face and } \\
\text { redden my lips. (148-49) }\end{array}$ & $\begin{array}{l}\text { CHORUS: "Ienni is no longer } \\
\text { young." } \\
\text { CHoRus: "She is no longer part } \\
\text { of the procession." } \\
\text { CHORus: "But she still powders } \\
\text { her face and reddens her lips!"" }\end{array}$ \\
\hline 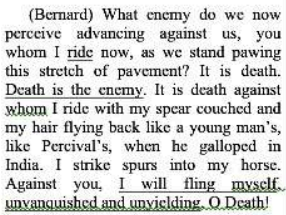 & $\begin{array}{l}\text { Percival: I am Percival. I will } \\
\text { ride my horse and fling myseclf } \\
\text { against death unvanquished, } \\
\text { unyielding! Death is the cnemy! }\end{array}$ \\
\hline
\end{tabular}

From novel to script: transformation types

As in Performing Mrs Dalloway (Lapaire 2018), the chorus is a central component in the script. Its members report major events and comment on the dramatic action, but also reflect upon the emotions and situations experienced by the 6 protagonists and their common "hero" Percival. To render the multiple perspective technique adopted by Woolf in The Waves, the viewpoints and narrative angles expressed by the chorus are split into fragments and undergo continuous change: they shift between "external" and "internal," "individual" and "communal," "empathic" and "sarcastic," "factual" and "metaphysical." Yet, unity and stability are achieved by maintaining a kind of ironic distance throughout.

The lines spoken by the chorus can be kept short and simple. It is easy to distribute them fairly and evenly among members of a large group. The form is well suited to students with little or no acting experience. Simple declaratives ("Tuesday follows Monday"/"We eat and drink"/"We marry and domesticate"); short verbless utterances ("Toast and butter; coffee and bacon"/"The Times and letters"); exclamations ("We have 
triumphed!"/"No, we have failed!") or descriptive statements ("Now they all walk down the avenue") are easy to "recite" or "act out." Conventional forms of dialogue would more challenging because they are based on face-to-face interaction and require mutual adjustment - a process that is more complex to handle for beginners.

\section{BREAKING VIRGINIA'S WAVES}

\section{PROLOGUE}

\section{(Take it. This is my life)}

BERNARD: I am not one person. I am many people. Bernard, Neville or Louis; Susan, Jinny or Rhoda. I am all of them. I can't distinguish my life from theirs.

RHODA (lost, with growing agitation): Who and what are these unknown people? What are stories?

JINNY (calm, with a touch of irony): There is always a story. I am a story!

Act 1 - Morning

(Childhood - Adolescence - Early adulthood)

(Scene 1) (The Nursery)

Poet: The sun is rising.

The light strikes upon the trees in the garden.

The wave pauses and draws out again,

Sighing like a sleeper whose breath comes and goes unconsciously.

Bernard: In the beginning there was the nursery, with windows opening on to a garden, and beyond that the sea.

Chorus: Six friends growing up together.

Chorus: "Let us explore!" they said.

Chorus: Susan, Jinny, and Rhoda.

Chorus: Bernard, Neville, and Louis.

Chorus: Skimming the flower-beds with their nets

Chorus: Brushing the surface of the world!

(All run away. Louis stays behind in the garden, hiding on the other side of the hedge).

Louis: Now they have all gone to the house. Now I am alone. They can't see me. (Standing by the wall among the flowers) My body is a stalk, my hair is made of leaves. My roots go down to the depths of the earth.

(Jinny comes back and finds him. She kisses him on the nape of the neck).

Jinny: I saw you, green as a bush and lying very still. I cried. 'Is he dead?' I cried and I ran; faster and faster.

Susan: I saw her kiss him. I saw them, Jinny and Louis kissing! I will not sit next to them anymore!

Bernard (drags Susan away): Let us run, let us explore. We shall sink like swimmers through the green air of the leaves. We shall sink as we run. The waves will close over us!

(School bell)

Chorus: Now they must drop their toys and games.

Chorus: Now is the time for Miss Hudson's lessons!

Chorus: Verbs and sums.

Chorus: The clock ticking in the classroom - tick-tick-tick.

Louis: I will not conjugate my verbs! I will wait and copy Bernard. He is English!

Chorus: They are all English except Louis.

Chorus: His father is a banker in Australia.

Rhoda: Now Miss Hudson has taken a lump of chalk. She draws figures, six, seven, eight, and then a cross and then a line on the blackboard. What is the answer?

Chorus: Rhoda cannot write.

Chorus: Now the terror is beginning 
Chorus: The figures mean nothing to her now. Meaning has gone.

(Scene 2) (Boarding school)

Poet: The sun rises higher.

The birds now sing wildly together.

The waves leave shallow pools of light here and there on the sand.

Chorus: The time has come for them to go to boarding school.

Chorus: Brothers and sisters separated!

Chorus: Eyes swell; eyes prick with tears.

Bernard: I mustn't cry!

Neville: The cab is at the door!

Louis: We shall all go on waving till we turn the corner!

Susan: The guard blows his whistle. The flag is dipped.

Jinny: We are passing through England in a train.

Rhoda: When we get there, I will be nobody. I will have no face.

Chorus: They have arrived.

Chorus: Boxes are unpacked in the dormitories.

Chorus: This is their first night at school.

Chorus: Now they march two by two into chapel.

Chorus: Now Dr Crane reads lessons from the Bible.

Neville: I hate this sad religion. I like the wine and the taverns of Ancient Rome. I like the naked boys sprawling in the dust. I like Percival's blue eyes in the school chapel, fixed with pagan indifference upon the pillars.

Chorus: Percival's movements are remarkable.

Chorus: He has the kind of beauty that one falls in love with for a lifetime, hopelessly!

Chorus: He will coarsen and snore.

Chorus: He will marry and there will be scenes of tenderness at breakfast.

Neville: But now Percival is young. He will throw off his coat and stand with his legs apart. He will lie naked on his bed.

Louis: It is Percival I need; for it is Percival who inspires poetry.

Bernard: When Percival talks, a lightness comes over me. It is Percival I need; for it is Percival who inspires poetry.

Chorus: Everybody follows Percival on the playground.

Chorus: He is thinking of nothing but the cricket match.

Chorus: He has the magnificence of some mediaeval commander.

Chorus: No, Percival is heavy. He makes foolish comparisons.

Chorus: They despise him! They won't suffer his stupidity!

Chorus: No, they envy him!

Chorus: Look at them, trooping after him!

Chorus: See, they adore him!

Susan: I say, school day, hated day! I hate Miss Perry's lessons. I hate the ugly stairs. I hate the orders to wash, to change, to work, to eat. I miss my home, I miss my father. I will never send my children to boarding school. Never!

Jinny: I move, I dance. I do not stand lost, like Susan, with tears in my eyes, remembering home.

Rhoda: I look at myself in the mirror but I have no face. Other people have faces; Susan and Jinny have faces. Their world is the real world. They say 'Yes', they say 'No'. They always know what to say! I want to fall. I want to be blown like a feather. Chorus: The time is coming when they shall leave school.

Chorus: Some will do this; others will do that.

Chorus: They will disperse, and the pressure will be over.

Chorus: The final ceremony is over!

Chorus: They are dismissed forever!

Jinny: Life is just beginning. Now my body can have a life of its own. Who's that gentleman there, sitting in the train, smiling at my reflection? 
Neville: Percival will forget me. I will send him letters and poems, and he will leave them lying about, unanswered. I will propose a meeting, and he won't come.

(Scene 3) (College and 'the real World')

Poet: The rising sun comes in at the window.

The wind rises.

The waves drum on the shore.

Neville: This is college, and I am now in love with Latin verbs, dictionaries and notebooks.

Bernard: This is college, and very hour something new is unburied. Who am I? I ask. This? No, I'm that!

Louis: This is the real world, and I sit in an office. I have become an average Englishman. I am an average clerk, poring over commercial documents.

Susan: They sent me to Switzerland to finish my education. I hate the linoleum; I hate the fir trees and the mountains.

Chorus: Susan will be like her mother, she will have children.

Chorus: She will lock up the cupboards.

Chorus: And watch the men on the farm with their pitchforks.

Jinny: This is London. This is my calling! This is my world! I glance, I peep, I powder.

I open and shut my body at my will.

Chorus: Men are attracted to Jinny. They approach her.

Chorus: 'O come' she says to this one. And he comes towards her.

Rhoda: I stand burning in this clumsy, this ill-fitting body.

Chorus: Rhoda is like a cork on a rough sea.

Chorus: Cast up and down among men and women.

Chorus: She is the foam that fills the rocks with whiteness, when the wave breaks.

Act 2 - Noon

(Adulthood - Percival's death)

(Scene 1) (Celebrating Percival's departure to India in a London restaurant)

Poet: The sun looks straight over the waves.

The sun falls on cornfields and woods.

Everything is without a shadow.

Bernard: Some people go to priests, others to poetry, I to my friends. My friends retrieve me from darkness.

Louis: We are all meeting for dinner tonight. We shall say good-bye to Percival, who is going to India.

Chorus: How proudly they sit in the restaurant!

Chorus: Eating and talking together.

Chorus: Bernard, Neville, and Louis.

Chorus: Susan, Jinny, and Rhoda.

Chorus: Here is Percival at last!

Chorus: Smoothing his hair.

Chorus: A hero - the God of decency.

Bernard (raising his glass): We have come together, at this particular time, in this particular place, because we are drawn by some deep emotion. Shall we call it 'love' - 'love of Percival'?

(In a series of asides)

Neville: Percival is going. I came here to sit by him, but I shall never have what I want.

Louis: Soon we will pay our bill and part again; soon the circle will break again. Susan: I despise the futility of London. I like to walk through the wet fields alone. Jinny: I kissed Louis once in the garden when we were little. Now I say to men 'Come'. Our hands touch. Our bodies burst into fire.

Rhoda: Percival's youth and beauty will soon be travelling through forests and far countries, wearing a sun helmet. Behold, Percival advances! Percival rides his horse! He is - a God!

Neville: Now the cab comes; now Percival goes; now the agony begins. 


\section{(Scene 2) (Percival dies)}

Poet: The sun has risen to its full height.

Now the sun burns, uncompromising.

Now the waves fall; withdraw and fall again

Like the thud of a great beast stamping.

Neville (holding the telegram): He is dead! Percival is dead! He fell. His horse tripped. He was thrown. All is over. The lights of the world have gone out.

Chorus: His horse stumbled; he was thrown. This is the fact.

Chorus: There was a surge, a drumming in his ears, then the blow.

Chorus: They carried him to some pavilion, men in riding-boots, men in sun helmets.

Chorus: Among unknown men he died.

Bernard: My son is born and Percival is dead!

Chorus: Percival sat there in the centre, and now the place is empty!

Chorus: He was twenty-five and should have lived to be eighty!

Chorus: Percival, a ridiculous name.

Chorus: Why hurry to the tube station? Why catch trains?

Chorus: Look at the street now that Percival is dead.

Chorus: It is strange how the dead leap out on us at street corners.

Rhoda: Now I want to be dashed like a stone on the rocks. I want to sink, with no one to save me!

(Scene 3) (Settling in life - Grief)

Poet: The sun no longer stands in the middle of the sky.

Now the light falls obliquely.

The waves mass themselves, curve their backs and crash.

Bernard: How does light return to the world after the eclipse of the sun? Miraculously: loveliness returns as one looks.

Louis: Miss Johnson brings me the letters in a tray. I sign them, again and again. Clear, firm, unequivocal. I have become a full-grown man. I love the telephone and the date on the wall, and the engagement book: Mr P. at four, Mrs E. at four-thirty. Not a moment to spare!

Chorus: Louis sends ships to the remotest parts of the globe.

Chorus: The weight of the world is on his shoulders.

Chorus: But he has kept his attic room.

Chorus: Rhoda sometimes comes, for they have become lovers.

Susan: Summer comes, and winter. The seasons pass. I sit by the fire watching the kettle boil. I stoop; I feed my baby. More will come, more children, more cradles, more baskets in the kitchen and hams ripening, and onions glistening!

Jinny: I have lived my life, I must tell you, and I am now past thirty. I do not attach myself to any one. And that man is a judge, and that man is a millionaire, and that man with the drooping moustache lives a life of the utmost debauchery! Life comes; life goes. I cannot tell you if life is this or that.

Neville: I revisit my past life, scene by scene. There lies Percival, forever and ever. I am now sitting alone with a man in the fire lit room, clutching his hand. But he is faithless and leaves me. The descent into the Tube is like death. I dream of naked cabin boys, squirting each other with hosepipes on the decks of ships! I feel ugly, dirty and weak.

\section{Act 3 - Late afternoon - Evening}

(Midlife)

(Scene 1) (The years)

Poet: The afternoon sun has sunk lower in the sky, warming the fields.

Birds swoop and circle high up in the air.

The sand is pearl white, smoothed and shining.

Bernard: My mind goes to an empty place and says: "I have lost my youth"

"I have lost Percival." I have outlived certain desires: my children... my wife... my house... my dog. 
Susan: I say, "My son"; I say, "My daughter." I see them casting shadows on the grass. I think sometimes of Percival who loved me. He rode and fell in India.

Chorus: At night, Susan hears her husband snore.

Chorus: The waves of her life toss and break around her.

Chorus: The tears, the violent passions of childhood are gone.

Neville: I take a book and read half a page of anything. I read poetry, I read Shakespeare here in Shaftesbury Avenue. I need not speak.

Louis: I have become immensely respectable. I hang my coat here, and place my stick there. Percival died, Rhoda left me. I have a little mistress - a vulgar little actress who will never speak English correctly!

Jenni: Here I stand in the Tube station. I am in the heart of life. But how solitary, how shrunk, how aged! Percival died. Millions have died! I still move. I still live. But who will come if I signal?

Chorus: Jenni is no longer young.

Chorus: She is no longer part of the procession.

Chorus: But she still powders her face and reddens her lips!

Rhoda: Oh life, how I have dreaded you! Oh human beings, how I have hated you!

(Scene 2) (Last reunion in London - Walking by the river together)

Poet: The sun is now sinking.

The shadows broaden on the hills.

The waves fall like a wall of grey stone.

Bernard: Hampton Court. This is the Inn. This is our last meeting place.

Chorus: Bernard, Neville, and Louis.

Chorus: Susan, Jinny, and Rhoda.

Chorus: Now they have aged.

Chorus: Some have turned grey; others gaunt.

Chorus: As they talk, time comes back.

Chorus: Marriage, death, travel, friendship.

Chorus: It was different once...

Chorus: They could have been anything!

Chorus: But change is no longer possible, now.

Chorus: The door will not open; Percival will not come.

Chorus: Rhoda says she has no face.

Chorus: "Waiter!" says one. "Bread!" says another.

Chorus: "It is time to go. The gardens will be shut!

Chorus: Now they all walk down the avenue.

Chorus: Arm-in-arm; hand-in-hand; leaning upon each other.

Chorus: One and indivisible!

Chorus: Now they stand by the river.

Chorus: "We have triumphed"; "No, we have failed!"

Chorus: "Love, love!" "My wasted life!" they say.

Chorus: Now they must go.

Chorus: Now the waves will spread between them.

Chorus: They will float for a moment - and then they will sink.

Epilogue

(And in me too the wave rises)

Louis: Life is pleasant. Life is good.

Chorus: Tuesday follows Monday.

Chorus: We eat and drink.

Chorus: Toast and butter; coffee and bacon!

Susan: We marry and domesticate.

Chorus: With shirts, socks, and the broken dreams of our unborn selves.

Chorus: With goodnights and see you tomorrows; and unfinished sentences!

Rhoda (depressed): The universal determination to go... on... living!

Percival (proudly and stupidly): I am Percival. I will ride my horse and fling myself against death, unvanquished, unyielding! Death is the enemy! 
Neville (looking at him lovingly): Percival, you are dead. You were thrown, riding in

a race.

Chorus: There is no plain and logical story.

Chorus: There is no past, no future; just the moment in its ring of light, and our bodies.

Chorus: Neville, Susan, Louis, Jinny, Rhoda, Bernard, Percival.

Jinny: Faces recur, faces and faces.

Chorus: We float. We are swept on by the torrent of things.

Chorus: We rise, we break, we pound on the shore.

Bernard: This is the eternal renewal - the incessant rise and fall, and rise again.

\section{BIBLIOGRAPHY}

The waves forever breaking on the shore.

Calbris, G. Elements of Meaning in Gesture. Amsterdam/Philadelphia: John Benjamins, 2011.

Clements, E. "Transforming Musical Sounds into Words: Narrative Method in Virginia Woolf's The Waves." Narrative, Vol. 13, No. 2 (May, 2005), 160-181.

Darinskaya, Daria. The Waves: a booktrailer. In Russian, with English subtitles. 2 :13, 2015. Retrieved from: https://www.youtube.com/watch?v=UDqNIqA5z-U

Eco, U., A Theory of Semiotics, Bloomington: Indiana University Press, 1979.

Flint, K. Introduction to The Waves (1931) by Virginia Woolf. London: Penguin Classics, 1992, ixxxxix.

Fodor, J. The language of thought. Cambridge, Mass.: Harvard University Press, 1975.

Hild, A. "Community/Communication in Woolf's The Waves: The Language of Motion." The Journal of Narrative Technique, Vol. 24, No. 1 (Winter, 1994), 69-79.

Jakobson, R. “On Linguistic Aspects of Translation.” In Brower (ed.), On

Translation. Cambridge, MA: Harvard University Press, 1959, 232-239.

Jousse, M. The Anthropology of Geste and Rhythm. Second revised edition, edited from the original French [1974-78] by Edgard Sienaert and translated in collaboration with Joan Conolly. Durban, South Africa: Mantis Publishing, 2010.

Jousse, M. The Fundamentals of Human Expression and Communication. Translated and presentd by Edgard Sienaert and Joan Conolly. Durban, South Africa: Mantis Publishing, 2005.

Langacker, R. Cognitive Grammar. An Introduction. Oxford: Oxford University Press, 2008.

Lapaire, J.-R. "Living speech or the bodily life of language." With Jean Magnard and Melissa Blanc. SKASE Journal of Theoretical Linguistics, Volume 12 - 2015, N 3, 528-541.

Lapaire, J.-R. “Say, display, replay: Erving Goffman meets Oscar Wilde.” Miranda 13 | 2016.

Lapaire, J-R., Duval, Hélène. To the Lighthouse (1927): a choreographic re-elaboration." Miranda, 15 | 2017.

Lapaire, J-R., “Performing Mrs Dalloway (1925).” Miranda, 17 | 2018. 
Lapaire, J-R. Engaging the 'learning body' in language education." English and American Studies, Issue $16 / 2019$.

Lindgren, R., Johnson-Glenberg, M. "Emboldened by Embodiment. Six Precepts for Research on Embodied Learning and Mixed Reality.” Educational Researcher, Vol 42, Issue 8, 2013, 445-452.

McGregor, W. Woolf Works. The Royal Ballet. Premiered at the Royal Opera House, London, 11 May 2015.

McNeill, D. Hand and Mind. What Gestures Reveal About Thought. Chicago: The University of Chicago Press, 1992.

Miko, S.J. "Reflections on The Waves: Virginia Woolf at the Limits of her Art." Criticism, Vol. 30, No. 1 (Winter, 1988), 63-90.

Nunnely, Mark. Wolf Works Insight. (The Royal Ballet). London, Royal Opera House: RSA Films, 2017. Retrieved from: https://www.youtube.com/watch?v=M0ADxUspPW8

O’Halloran, K., Tan, S., Wignell, P. “Intersemiotic Translation as Resemiotisation: A Multimodal Perspective." Signata, $7 \mid 2016$

Piazzoli, E. Embodying Language in Action. The Artistry of Process Drama in Second Language Acquisition. Cham: Palgrave Macmillan, 2018.

Richardson, R.O. "Point of View in Virginia Woolf's The Waves." Texas Studies in Literature and Language, Vol. 14, No. 4 (Winter 1973), 691-709.

Schewe, M. "Taking Stock and Looking Ahead: Drama Pedagogy as a Gateway to a Performative Teaching and Learning Culture." Scenario, Volume 2013, Issue 1.

Sienaert, E. "Introduction à deux cours d'anthropologie de Marcel Jousse. " Nunc, revue anthropologique, $\mathrm{n}^{\circ} 25,2011,38-47$.

Skulmowski, A., Rey, G.D. “Bodily Effort Enhances Learning and Metacognition: Investigating the Relation Between Physical Effort and Cognition Using Dual-Process Models of Embodiment." Advances in Cognitive Psychology, Volume 13 (1), 2017, 3-10.

Whorf, B. “Grammatical Categories.” Language, Vol. 21, No. 1. (Jan. - Mar., 1945), 1-11.

Woolf, V. The Waves. London: Penguin Classics, [1931] 2000.

\section{NOTES}

1. Critics usually consider this last italicized sentence to be the tenth and last interlude (Clements 2005: 166).

2.

[First section. Opening sentences, supposedly uttered by infants walking through the garden] 'I see a crimson tassel,' said Jinny, 'twisted with gold threads.' (...) 'A shadow falls on the path,' said Louis, 'like an elbow bent.' 'Islands of light are swimming on the grass,' said Rhoda. (Woolf [1931] 2000: 5)

3.

For a definition of "interlingual" and "intersemiotic" translation see Jakobson (1959) or the "trans-semiotic adaptation" section further on.

4. 
Interpret vb. 1. to clarify or explain the meaning of; elucidate. 2. to construe the significance or intention of : to interpret a smile as an invitation. 3. to convey or represent the spirit or meaning of (a poem, a song, etc.) in performance. 4. (intr.) to act as an interpreter; translate orally.[ from Lat. interpretari, from interpres negotiator, one who explains" (Collins English Dictionary, 1979). Senses 1 and 2 clearly highlight the cognitive dimension of interpretation ("explain", "construe"), while 3 and 4 respectively underscore the performative and trans-semiotic dimensions of the interpretive process. The claim I make here and elsewhere (Lapaire 2019), is that all the three main senses are - cognitive, performative, translational - are fundamentally related and interdependent. The ability to construe, act out and transpose is part of our common human "interpretive potential".

5.

O'Halloran et al. (2016) note that "viewing intersemiotic translation as resemiotisation" raises major issues, such as "how can shifts of meaning be conceptualised across semiotic resources which are fundamentally different in nature?" and "what meanings are retained and changed as a result of resemiotisation?"

6.

Ludovica Rambelli Teatro. URL : https://www.ludovicarambelliteatro.it/tableaux-vivants/

7.

Now a certain man was sick, named Lazarus, of Bethany, the town of Mary and her sister Martha (...) Therefore his sisters sent unto him, saying, Lord, behold, he whom thou lovest is sick (...) Then when Jesus came, he found that he had lain in the grave four days already (...) Then when Mary was come where Jesus was, and saw him, she fell down at his feet, saying unto him, Lord, if thou hadst been here, my brother had not died. When Jesus therefore saw her weeping, and the Jews also weeping which came with her, he groaned in the spirit, and was troubled. And said, Where have ye laid him? (...) It was a cave, and a stone lay upon it (...) Then they took away the stone from the place where the dead was laid. And Jesus lifted up his eyes, and said, Father, I thank thee that thou hast heard me (...) And when he thus had spoken, he cried with a loud voice, Lazarus, come forth. And he that was dead came forth, bound hand and foot with graveclothes: and his face was bound about with a napkin. Jesus saith unto them, Loose him, and let him go." (John, 11: 1-44) King James Version (1611).

8.

Université Bordeaux Montaigne, France.

9.

"Langues vivantes en vie: rejeux vocaux et gestuels de l'expérience" (Lapaire, Magnard \& Blanc, Université Victor Ségalen, Bordeaux FR, 2013); “Le corps dans la langue: imprimer, exprimer, dérouler / Der Leib in der Sprache - einprägen, ausdrücken, entfalten” (Lapaire, Magnard \& Blanc, Goethe Institut, Paris FR, 2014); "Moved by Language" (Lapaire, Magnard \& Blanc, Vercelli IT, 2014); "La poétique du geste" (Lapaire, Magnard \& Blanc, Univeristé de la Sorbonne Nouvelle, Paris FR, 2015); "Chorégraphie de la parole" (Lapaire \& Blanc, Université de Montpellier 3 FR, 2015); Poetic-kinetic intervals" and "Motion Capture" (Lapaire, Magnard \& Blanc, Vercelli IT, 2015).

10.

The title contains an allusion to Lars Von Trier's film Breaking the Waves (1996), with Emily Watson (Bess) and Stellan Skarsgard (Jan).

11.

The workshops were held at Maison des Arts, Pessac, on the main UBM campus site.

12.

Oliver Borowski (4 h) ; Melissa (2h) ; Melissa and Oliver (3h).

13. 
How physical displays may be given of affect, inner states, and the impact of own's own words upon oneself.

14.

Master in English language and literature studies: Sarah Baudouin, Camille Boscher, Apolline Boulesques, Eneko Dufourg, Julien Escaffre, Rozenn Hochard, Daley Ann Pamela King, Monica Minix, Melissa Paulin, Lucas Prunier. Master in Drama and Performance Studies: Julie Cabaret, Sarah Caillaud, Célestine Fisse, Alexandre Gauzentes.

\section{ABSTRACTS}

Dance space and theatre space can be used as critical thinking spaces in the language and literature class, with substantial gains in student motivation and engagement. This claim was put to the test with a group of 38 graduate students who co-designed a stage adaptation of Virginia Woolf's experimental novel The Waves (1931) using acting and dance-composition techniques. Woolf's 77 480 -word piece (225 pages) was reduced to $3,4 \%$ of its original length ( 2684 words, 7 pages). The experience was creative (reprocessing and essentializing rich textual input, designing scenes, tableaux and movement sequences); heuristic (investigating narrative technique, discovering elements of patterning and consistency below the surface of a complex and confusing narrative); socially cohesive (fostering mutual-support, developing collective forms of understanding, stage directing and acting); and immersive (stimulating all the senses, involving body and mind with few pauses and no opt out). Conditions were thus created for subjects to engage in verbal, visual and kinaesthetic acts of interpretation in all three senses of the word: cognitive ("understanding"), artistic ("performing") and intersemiotic ("translating" into a different sign system). As this happened, students found themselves cast in the role of moving and speaking cognizers, staging bodily displays of meaning, and reframing Woolf's written narrative as a series of "acts" and "scenes" to be performed - not just read. A form of semiotic appropriation took place that resulted in a performative reassignment of meaning which not only "made sense" to movers and viewers alike, but struck everyone as being plastic, aesthetic, and compelling.

This article provides textual and visual illustrations of the remarkable result achieved by the graduate students involved, under the professional guidance of Oliver Borowski (theatre) and Melissa Blanc (dance). It includes the script and visuals from the workshops held at Université Bordeaux Montaigne (France), and an evocation of the final public performance given at Teatro Civico (Vercelli, Italy) at the international student theatre festival organized by Università del Piemonte Orientale (TILLIT 2019, dir. Marco Pustianaz).

\section{INDEX}

Subjects: Music, Dance

Keywords: choreography, adapation, intersemiotic translation, resemiotisation, performance, enaction, creativity, embodied learning

Mots-clés: chorégraphie, adaptation, traduction intersémiotique, resemiotisation, performance, enaction, créativité, apprentissage par-corps 
AUTHORS

JEAN-RÉMI LAPAIRE

Professor

EA CLIMAS / Université Bordeaux Montaigne

jrlapaire@u-bordeaux-montaigne.fr 